This document was prepared in conjunction with work accomplished under Contract No. DE-AC09-96SR18500 with the U. S. Department of Energy.

\title{
DISCLAIMER
}

This report was prepared as an account of work sponsored by an agency of the United States Government. Neither the United States Government nor any agency thereof, nor any of their employees, makes any warranty, express or implied, or assumes any legal liability or responsibility for the accuracy, completeness, or usefulness of any information, apparatus, product or process disclosed, or represents that its use would not infringe privately owned rights. Reference herein to any specific commercial product, process or service by trade name, trademark, manufacturer, or otherwise does not necessarily constitute or imply its endorsement, recommendation, or favoring by the United States Government or any agency thereof. The views and opinions of authors expressed herein do not necessarily state or reflect those of the United States Government or any agency thereof.

This report has been reproduced directly from the best available copy.

Available for sale to the public, in paper, from: U.S. Department of Commerce, National Technical Information Service, 5285 Port Royal Road, Springfield, VA 22161, phone: (800) 553-6847, fax: (703) 605-6900

email: orders@ntis.fedworld.gov

online ordering: http://www.ntis.gov/help/index.asp

Available electronically at http://www.osti.gov/bridge

Available for a processing fee to U.S. Department of Energy and its contractors, in paper, from: U.S. Department of Energy, Office of Scientific and Technical Information, P.O. Box 62, Oak Ridge, TN 37831-0062,

phone: (865)576-8401,

fax: (865)576-5728

email: $\underline{\text { reports@ adonis.osti.gov }}$ 


\section{Statistical Analysis of Elevated Radium and Gross Alpha Measurements in the Sanitary Landfill}

April 12, 2004

Document No. WSRC-TR-2004-00141

Cary Tuckfield, Rachel Baker, and Miles Denham Savannah River Technology Center 


\section{INTRODUCTION}

In 2002, radium ( $\mathrm{Ra}) 226$ and 228 measurements elevated above the $5 \mathrm{pCi} / \mathrm{L}$ groundwater protection standard (GWPS) and gross alpha measurements above the $15 \mathrm{pCi} / \mathrm{L}$ GWPS were noticed in several groundwater monitoring wells at the SRS Sanitary Landfill (SLF). An additional four quarters of confirmatory measurements for Ra in the SLF groundwater were taken during 2003 as directed by the SC Department of Health and Environmental Control (DHEC).

Elevated radium concentrations in groundwater of the Aiken County area are a common occurrence. Price and Michel (1990) compiled radium concentrations in drinking water wells of this area and showed several instances of the concentrations exceeding the regulatory limit. Ra226 is an alpha emitter and contributes much of the natural alpha radioactivity found in uncontaminated groundwater. Thus, the elevated radium concentrations are usually accompanied by elevated gross alpha concentrations. Appendix A2 indicates that this is the case at the SLF where Ra226 accounts for almost all elevated gross alpha.

\subsection{Problem Statement}

The Annual 2002 Sanitary Landfill Groundwater Monitoring Report (WSRC 2003) shows exceedences for radium and gross alpha in the groundwater from $4^{\text {th }}$ quarter 2002 through $3^{\text {rd }}$ quarter 2003. In addition, the 2003 data show that 17 monitoring wells in the SLF network are confirmed as having elevated Ra226, or 228 , or a sum of these radioisotopes above the $5 \mathrm{pCi} / \mathrm{L}$ GWPS. The 17 are LFP series wells 5WP, 6WP, and 13WP and LFW series wells 8R, 18, 23R, 29, 36R, 41R, 45D, 47C, 57B, 62B, 64C, 66B, 67B, and 69C.

The problem presented to SRTC was whether these elevated data are consistent with groundwater impacted by SLF leachate or whether they are typical of natural conditions and therefore unlikely to have derived from anthropogenic inputs.

\subsubsection{Focus of Solution}

The solution to this problem will require the comparison of recent Ra measurements among these 17 monitoring wells to the past measurements in the same wells, and, if possible, comparison of the data from the SLF network to other groundwater monitoring well data from radiologically unimpacted SRS and non-SRS facilities.

\subsubsection{Working Hypothesis}

Because the facility in question is a sanitary landfill and therefore has no record of receiving radioactive waste, the working hypothesis is that the appearance of these radionuclides in recent groundwater samples is non-anthropogenic in origin.

\subsubsection{Lines of Evidence}


To accept the above hypothesis, it is requisite to demonstrate multiple lines of evidence as a convincing argument in favor of that hypothesis. Statistical data display methods will be used to compare recent and historical SLF radium data and to compare SLF radium data with that from other on- and off-Site wells, and correlation analysis will be used to examine relationships of SLF radium with different constituents and water quality parameters.

The principles of geochemistry suggest that elevated measurements of some radioisotopes should be correlated with elevated measurements in other analytes. Geoscience will be used to develop additional lines of evidence in support of the hypothesis by comparing Ra concentrations to other groundwater chemistry and water quality measurements as discussed in section 3.3 below.

\section{MONITORING WELL NETWORK DESCRIPTION}

The SLF groundwater monitoring network consists of LFW and LFP monitoring wells that are sampled regularly and often quarterly for a variety of constituents of concern (COCs) as specified in the 1992 SLF Postclosure RCRA Part B Permit Renewal Application (WSRC 1993). A more thorough description of the groundwater monitoring program for the SLF can be found in the Sanitary Landfill Groundwater Quality Assessment (GWQAP) (WSRC 1995).

\section{DATA AND METHODS}

This section describes the data used to generate the multiple lines of evidence in support of the working hypothesis and the statistical and geological science methodology used to test the working hypothesis.

\subsection{Data Sources}

Analytical, field, and depth to water data and well information for the Sanitary Landfill LFP and LFW series wells were retrieved from ERDMS, the Environmental Restoration Data Management System, for this analysis. Version 8.2 of the SAS System for Windows from SAS Institute was utilized to obtain and analyze the data and to produce various types of plots.

The analytes of concern are Ra226, Ra228, and gross alpha (ALPHAG). Analytes investigated for possible correlation with/ impact on the analytes of concern include other rads, barium (BA), and calcium (CA). Turbidity, $\mathrm{pH}$, alkalinity (as $\mathrm{CaCO} 3$ ), and purge volume were the field analytes studied. For the analytical data, the well, analyte name and testcode, sample date and time, analysis date, sample type (to exclude field QC samples), analysis code (to exclude lab QC results), analyte type (to exclude tentatively identified compounds-TICs and surrogates), sample matrix (groundwater only), result and units, review and lab qualifiers, qualification codes, lab, analytical method, filter code (for metals), sample quantitation limit (SQL) and units, and validation \& verification status were pulled. The subset of variables applicable to field measurements was retrieved for the field and depth to water data.

For the analytical data, the result qualifier was defined from the lab and review qualifiers, and 
the units were all converted to a consistent basis for the result and the SQL. Detection was determined from the result qualifier, and then an adjusted result for nondetects was set as follows. Half of the SQL was the preferred estimate for nondetects, as is standard with environmental data. If the SQL was missing or invalid, the result was used: half of the result for chemical analytes and the result itself for rad analytes (or zero for rad results less than zero). Data with missing sample dates, invalid or inconsistent units, rejected results (result qualifier of $\mathrm{R}$ ), or invalid results (validation and verification status of VI) were deleted. The field and depth to water data were similarly screened. Hold times for Ra226, Ra228, and gross alpha were assessed as the time from sampling to analysis, and none of the hold times exceeded the current limit of 180 days. Water elevation was calculated from the well reference elevation less the measured depth to water.

The analyte testcode Ra2628 was created to represent the sum of Ra226 and Ra228. The highest result for each well, analyte, sample date, and lab was identified from detected data. If there were no detects, the highest adjusted result from the nondetects was chosen. The selected Ra226 and $\mathrm{Ra} 228$ results were added together, and a detection value was determined to indicate whether the Ra2628 value represented a below detect, detect, or combination (Ra226 detect and Ra228 nondetect or vice versa).

In addition to the concentration of the radium analytes, the ratio of Ra228 to Ra226 was examined. The max detected result for each well, analyte, sample date, and lab was identified, and then the isotopic ratio was calculated from these results. Detects only were included since ratios of differing detection limits do not have much bearing on concentration ratios.

The analytical data were then averaged sequentially to obtain quarter averages for the correlation analyses. Data for an analyte in a well were averaged over replicates to derive method averages, over methods to derive lab averages, over labs to derive sample date averages, and over sample dates to derive quarter averages. Note that adjusted results were substituted for nondetects in the calculations. Field data and water elevations were processed in the same way to return quarter averages.

ERDMS has information for $124 \mathrm{LFP} / \mathrm{LFW}$ wells. Each of the wells was assigned a category based on the concentrations of Ra2628 and the associated sample dates. Concentrations of 5 $\mathrm{pCi} / \mathrm{L}$ or above are considered elevated. Wells with elevated detected Ra2628 results from 2003 to present were classified as "Ra recent," and wells with elevated detected Ra2628 results from prior to 2003 only were labeled as "Ra old." Wells with no elevated detected Ra2628 but with elevated detected gross alpha were classified as "ALPHAG only." Some wells had no elevated concentrations of Ra2628 or of gross alpha or had no data at all. Of the 124 wells, there were 17 "Ra recent" wells, 57 "Ra old" wells, 14 "ALPHAG only" wells, 23 wells with no elevated concentrations, and 13 wells with no data. This breakdown reveals that $2 / 3$ of the wells with data exhibited a problem with radium at some point. The focus of the analysis was on the 17 wells with recent Ra2628 elevated values: LFP 5WP, 6WP, 13WP; LFW 8R, 18, 23R, 29, 36R, 41R, 45D, 47C, 57B, 62B, 64C, 66B, 67B, 69C.

Refer to Appendix A1 for a listing of all SLF wells with summary information. Appendix A2 compiles detection data for all radioactive analytes from the SLF wells. 
Data from the SLF wells were compared to data from other well groups on Site and to data from a study of natural radioactivity conducted in the local area (Price and Michel 1990). The DCB 18, 19, 21, 22, and 24 well clusters; P series wells; and C series wells on Site are known to have natural radium only. Based on Ra228/Ra226 ratios, Denham et al. (1999) concluded that the primary source of radium in the DCB wells is the native soils. The evidence suggests that acidic groundwater from the nearby coal storage pile leaches radium from soils of the aquifer. This, combined with some radium from the coal itself, results in elevated radium concentrations. The $\mathrm{P}$ series wells were installed at the SRS to provide information on groundwater flow and quality in uncontaminated background areas. The $\mathrm{C}$ series wells are similar but were installed off-Site by the state of South Carolina. (The C series wells had no data in ERDMS.) The data from the study of natural radioactivity were divided into groups of on-Site and off-Site wells. Since some of the non-SLF data had extremely high detection limits, only detected data were involved in the comparison.

\subsection{Statistical Methods}

Perhaps the simplest and most illustrative statistical method for providing evidence for or against a hypothesis is in the use of data displays. This report provides

- Time series plots - to illustrate the contaminant concentration data over time relative to the GWPS

- Box-and-whisker plots - to illustrate the comparison of Ra measurements in the SLF groundwater to Ra measurements in other on- and off-Site groundwater monitoring wells

- Correlation analyses - to describe the tendency of Ra measurements to increase or decrease in relation to corresponding increases or decreases in other measured values such as water quality variables

- Simple linear regression (SLR) and Orthogonal regression models - to compare the slopes of the linear relationships between $\mathrm{Ra}$ and other groundwater variables suggested by the correlation analyses.

A box-and-whisker plot (or simply boxplot) consists of a box around the middle $50 \%$ of the data, with a center line representing the median and a dot for the average. Lines called whiskers are drawn from the $25^{\text {th }}$ quantile (bottom of box) to the smallest observation and from the $75^{\text {th }}$ quantile (top of box) to the largest observation. Comparison of boxplots is a nonparametric approach to data analysis, meaning that assumptions about the distribution of the data population are not needed.

Simple linear regression (SLR) is a method in which a predictor variable is used to model a response variable using a straight line. The best fit minimizes the differences between the predicted and observed values of the response variable. Orthogonal regression differs from SLR in that the there is assumed to be measurement uncertainty (i.e. variation) in regressor (X) variable as well as the response (Y) variable. This method then finds the best estimate of the slope and intercept parameters for the fitted line by minimizing the sum of the squared perpendicular distances from the X,Y coordinates of each data point to that regression line and not to the $\mathrm{X}$ axis as is typical in SLR. 
Common logarithms were used in many of the plots and analyses, because the data on the original scale cross more than one order of magnitude.

The time series plots and boxplots were generated using the $\mathrm{SAS}^{\odot} 8.2$ statistical computing software on a PC running Microsoft Windows 2000. All other statistical analyses were performed using the JMP ${ }^{\odot} 5.01$ software on the same computer platform. Both are products of the SAS Institute, Cary, NC. The statistical methods described above are explained in SAS (2000) and JMP (2000) reference documentation.

\subsection{Geochemistry}

Radium is a naturally occurring radionuclide in the alkaline earth group of elements. Its geochemical behavior is similar to other alkaline earths such as calcium, strontium, and barium. In uncontaminated aquifers, Ra226 is generated from decay of U238 while Ra228 is produced from decay of Th232. Most of the radium in an aquifer is bound in minerals that contain uranium and thorium but can be released to groundwater if the mineral dissolves. Alpha recoil can also eject radium from the lattice of a mineral directly into groundwater. Once in groundwater, radium is subject to adsorption on aquifer mineral surfaces. Adsorption/desorption is related to chemistry of the groundwater with adsorption being stronger with increasing $\mathrm{pH}$. Thus, it is expected that radium concentrations in groundwater should correlate with certain other parameters.

Prior to developing geochemical arguments about observed radium behavior in groundwater, it must be determined whether the data are a true reflection of groundwater conditions. Sampling conditions or analytical error can lead to the appearance of elevated concentrations of radium. The sampling condition most likely to affect radium concentrations is collection of turbid samples. Radium, as with other metals, can adhere to clay particles in a turbid sample (depending on sample preparation methods), resulting in radium concentrations greater than the actual dissolved concentration. If this is the cause, radium should correlate with turbidity. Analytical errors or biases can also give the appearance of elevated radium concentrations. If this is the case, elevated radium isotope concentrations should not correlate with other parameters.

The factors that affect concentrations of other alkaline earths in groundwater should also affect radium concentrations. However, any relation between radium concentrations and concentrations of non-radioactive constituents may be obscured by the large difference in mass concentrations between radium and other constituents. When converted to mass concentrations, $10 \mathrm{pCi} / \mathrm{L}$ of Ra226 is $3.1 \times 10^{-14}$ moles/L; $10 \mathrm{pCi} / \mathrm{L}$ of $\mathrm{Ra} 228$ is $1.1 \times 10^{-16}$ moles/L. Most other natural constituents are present at concentrations that are several orders of magnitude greater than these. For example, groundwater with a barium concentration of $1 \mathrm{ug} / \mathrm{L}\left(7.3 \times 10^{-9}\right.$ moles/L) and a radium concentration of $10 \mathrm{pCi} / \mathrm{L}$ contains about 200,000 times more barium ions than $\mathrm{Ra} 226$ ions and about 66 million times more barium ions than Ra228 ions. Thus, correlative concentrations of radium and most non-radioactive constituents may not be detectable, because measurable changes in radium concentrations often correspond to undetectably small changes in other constituents. 
Sulfate concentrations can also be correlative with radium concentrations if a sulfate phase such as barite $\left(\mathrm{BaSO}_{4}\right)$ is near saturation in the aquifer. Increases in sulfate concentration will cause the sulfate phase to precipitate, removing radium by co-precipitation. In this case, radium would be inversely correlated with sulfate. Conversely, positive correlations could result from dissolution of a sulfate mineral containing radium or could simply be coincidental. However, barium concentrations in SLF groundwater show no relation to sulfate concentrations and are well below saturation with barite. This indicates that another non-sulfate phase is controlling barium concentrations and probably radium concentrations. Thus, any trend of radium with sulfate may be a spatial rather than a geochemical relation or may reflect independent covariation of radium and sulfate with another parameter. If the trend occurs only within the defined plume boundaries, then it is likely that some property of the landfill leachate is capable of mobilizing radium and sulfate. The property could be high ionic strength, acidity, high chloride concentrations, dissolved organic matter, or a combination of these.

This emphasizes the fact that elevated radium concentrations in groundwater associated with a waste site can be caused by three mechanisms:

- Leaching of radium from disposed materials in the waste site

- Leaching of natural aquifer radium by some component of the waste site leachate

- Natural variations in groundwater chemistry

If the radium is from natural variations, then the variations in concentrations should be consistent with variations in groundwater from uncontaminated areas of the same region.

Radium isotopes are an important indicator of the origin of elevated radium concentrations in groundwater. A daughter of Th232 with a half-life of 5.75 years, Ra228 will reach secular equilibrium with Th232 in less than 60 years. A daughter in the decay chain of U238 with a halflife of 1600 years, Ra226 will take over 2 million years to reach secular equilibrium with $\mathrm{U} 238$. At a site where processed Th232 was disposed, Ra228 concentrations may be elevated from decay of the Th232. In contrast, elevated concentrations of Ra226 cannot be derived from disposal of processed U238 within a reasonable time frame. Thus, an explanation for elevated radium concentrations

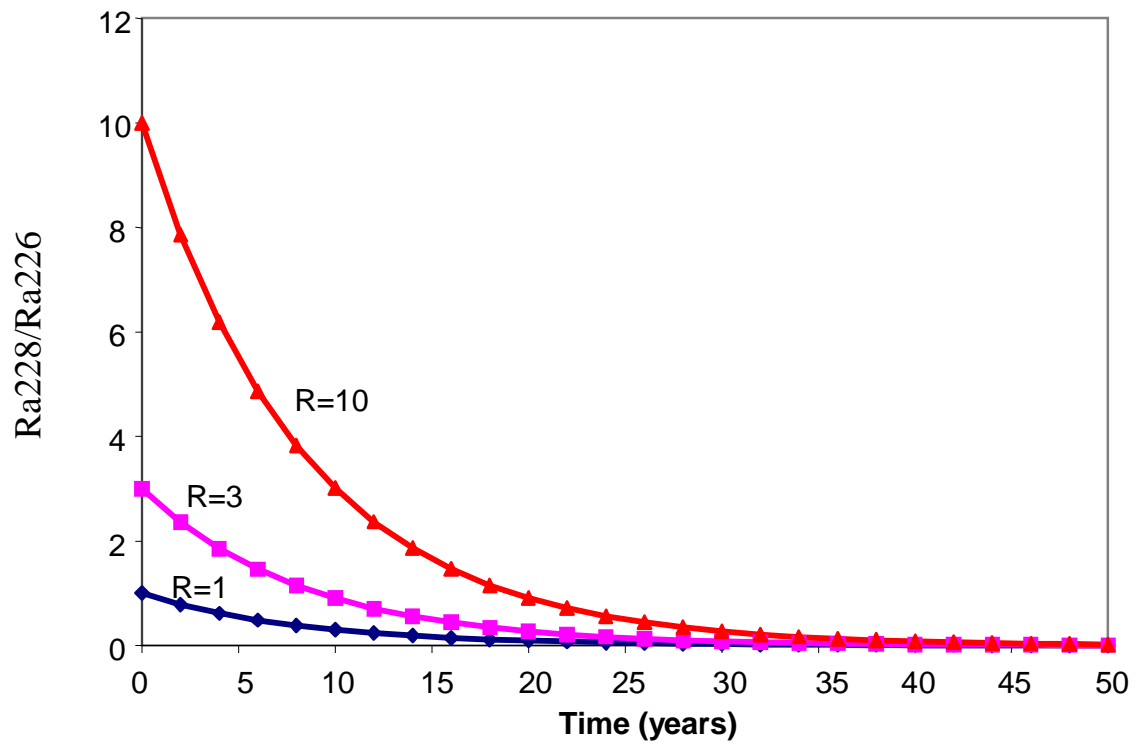

Figure 1. Calculated Ra228/Ra226 ratios with time. $R$ is the initial ratio. 
must account for the $\mathrm{Ra} 228 / \mathrm{Ra} 226$ ratio, as well as for the actual concentrations.

Radium emanating from a point source such as a disposal site should show a systematic variation in the $\mathrm{Ra} 228 / \mathrm{Ra} 226$ ratio within the plume due to the different half-lives of the two isotopes. As radium moves with groundwater, the ratio decreases because of Ra228 decay relative to Ra226 (Figure 1). Consistent $\mathrm{Ra} 228 / \mathrm{Ra} 226$ ratios over a large area are suggestive of a native rock rather than a point source for radium within a waste site.

\section{RESULTS}

The data results will be in two formats, viz., within individual wells and across all wells. Ra isotopic and gross alpha (ALPHAG) data were used to generate data displays for each well in the SLF; however it is sufficient to portray these results for only the 17 recently identified wells with elevated Ra measurements.

\subsection{Data Reliability}

Prior to performing statistical analyses for testing the working hypothesis, concerns relative to data reliability were resolved first. This was accomplished by comparing the relationships between Ra226 and Ra228 versus ALPHAG. Although Ra228 is not an alpha emitter, it is often related geochemically (see section 3.3) to Ra226 and therefore should show a positive correlation with ALPHAG. Also, each of these variables is usually analyzed by different methods, and laboratory measurement error should not propagate between the methods.

Figure 2 is a plot of quarterly measurement data for all SLF wells and shows that both Ra226 and Ra228 are, in fact, positively correlated with ALPHAG. This supports the expected relationship based on geochemistry, and therefore the data obtained from the Site environmental database (ERDMS) are considered to be reliable.

\subsection{Spatial Evidence}

Figure 3 is a spatial map of the SLF monitoring well network that also includes special symbols (black stars) lying on top of the well locations to show the source of the recently elevated

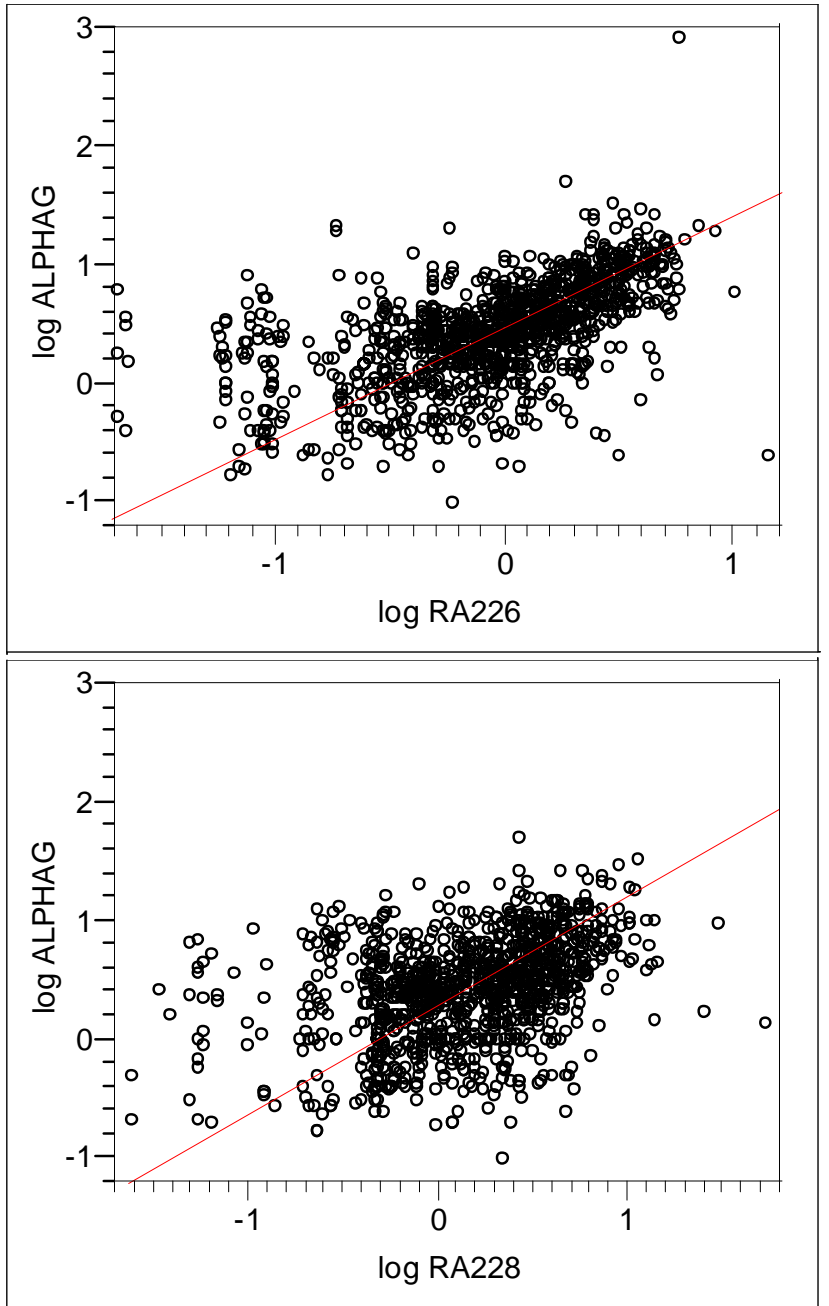

Figure 2. Plots of Ra226 and Ra228 versus Gross Alpha on common log scale showing strong positive $(p<.05)$ correlation between both pairs of variables. 
FINAL REPORT: Ra in the SLF WSRC-TR-2004-00141

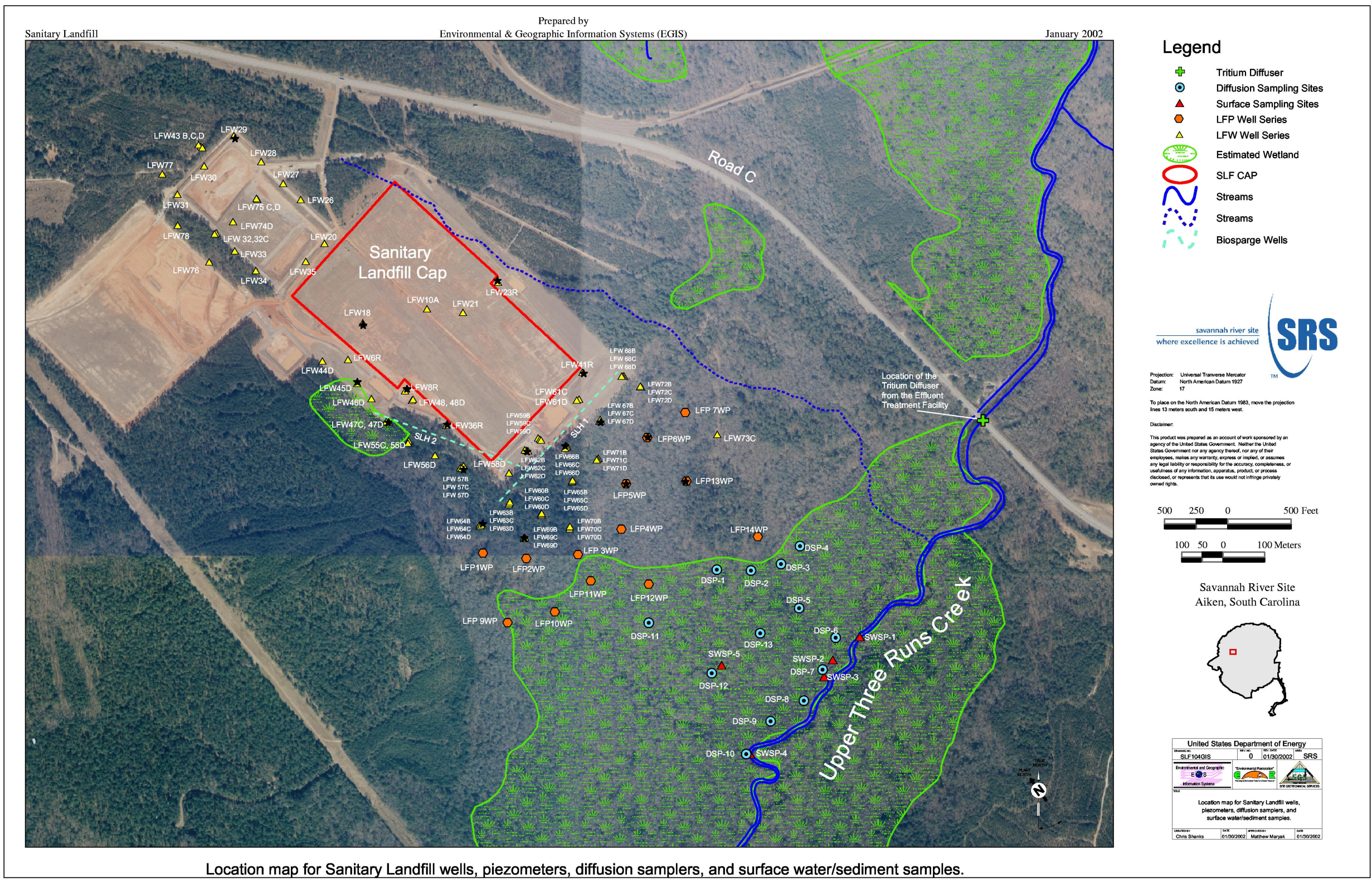

Figure 3: Spatial map of SLF with black stars indicating wells with recently elevated radium. 
measurements of Ra isotopes. Note that even though most of the elevated measurements are located downgradient to the SLF facility there are also elevated measurements in at least one upgradient well (LFW 29). In addition, there is no consistent spatial pattern for Ra contamination in the downgradient wells. Ra exceedences in the LFW 62 cluster, for instance, would be expected to appear in other downgradient well clusters in close proximity to LFW 62 , but do not.

\subsection{Total Ra Analysis}

The GWPS for radium does not allow concentrations of Ra226, Ra228, or sum of these two isotopes ( $\mathrm{Ra} 2628)$ to exceed $5 \mathrm{pCi} / \mathrm{L}$.

\subsubsection{Wells with Recent Exceedences}

The time series plots for the 17 wells with recent (2003) elevated Ra measurements above the GWPS are shown in Appendix B1. For each well, the concentration is depicted through time for Ra226, Ra228, Ra2628, and gross alpha on a single plot. The plot symbol color indicates detection; the plot symbol denotes the lab; and colored lines distinguish analytes. Most of the plots have the same sample date scale (January 1987 January 2004) and result scale (0-70 pCi/L) for easy comparison of wells. The only exception is the result scale for LFP $5 \mathrm{WP}$, which has a gross alpha result of $839 \mathrm{pCi} / \mathrm{L}$ (and an SQL of $633 \mathrm{pCi} / \mathrm{L}$ ) on 6/28/2002. Since the next highest gross alpha result from all of the SLF wells through all time is $69.1 \mathrm{pCi} / \mathrm{L}$, this is obviously an extreme (and suspect) outlier. The three LFP wells have only recent data, but the plots for most of the LFW wells portray analyte concentrations that are relatively consistent through time.

These results show not only the recently elevated Ra results, but that also Ra has shown historically elevated concentrations. For instance, the Appendix B1 plot for LFW 18 shows that Ra2628 was elevated above the GWPS during the mid 1990's as well as in 2003 primarily due to Ra228.

\subsubsection{Historical Ra and Gross Alpha Concentrations}

Appendix B2 displays time series plots by analyte for all SLF wells in this study. These plots were constructed for Ra226, Ra228, Ra2628 (sum), and gross alpha and for the ratio of detected Ra228 to Ra226. All of the SLF data were included in the plots for the purpose of examining the radium or gross alpha concentrations through time for all SLF wells. The plot symbol color indicates detection, and the plot symbol distinguishes the lab. Note that some of the gross alpha values, both detects and nondetects, in the 2000 to 2001 time frame seem high relative to the surrounding data, and that only the Mobile Lab performed those analyses. The levels of each analyte appear to be consistent through time, with the exception of the afore-mentioned gross alpha values from the Mobile Lab. Note that of the 111 SLF wells with data in this study, 42 of them showed concentrations of gross alpha elevated above the $15 \mathrm{pCi} / \mathrm{L}$ GWPS. This fact has also been presented in a similar data display in the 2004 Noffsinger report ERD-EN-2004-0087. 
FINAL REPORT: Ra in the SLF

WSRC-TR-2004-00141

\subsection{Radium Isotopic Ratio Analysis - On-Site versus Off-Site Ra Comparisons}

The ratio of the two Ra isotopes (228 to 226) was constructed to assess the weight of evidence for an anthropogenic source of radium in the SLF. Ratios that are relatively constant in the SLF wells by comparison to ratios in the wells of other on- and off-Site facilities would be regarded as evidence in favor of the working hypothesis. Data from the study "Radioactivity in Groundwater near the Savannah River Site" (Price and Michel 1990) were utilized in this analysis.

Sets of boxplots were drawn for detected Ra226, detected Ra228, detected gross alpha, and detected isotopic ratios for the SLF wells, selected DCB series wells, P series wells, study wells from on-Site, and study wells from off-Site. Only detects were involved in this analysis since some of the non-SLF data had overly large detection limits, which made the plots misleading. Common logarithms of the data were used to better show the variability of these ratios among the on- and off-Site groups of wells, because the measurement ratios among wells often crossed one or more orders of magnitude. For each set of plots, reference lines were built from the $25^{\text {th }}$ and $75^{\text {th }}$ quantiles of the SLF boxplot. The overlap of the boxes on every plot indicates that the SLF values are not significantly different from those of the other groups.

Figure 4 is a set of boxplots depicting the results of the comparison for the isotopic ratio. The Figure shows that the SLF radium ratios are not unlike those among wells in other facilities known to have natural radium only. The DCB ratios are slightly higher than others because the radium is a mixture of radium from native soils and radium from coal (ratio of about 1.3). This suggests that the SLF ratios are in line with what would be expected from naturally occurring radium, and, therefore, that natural variations in radium concentration could account for the radium exceedences at the SLF.

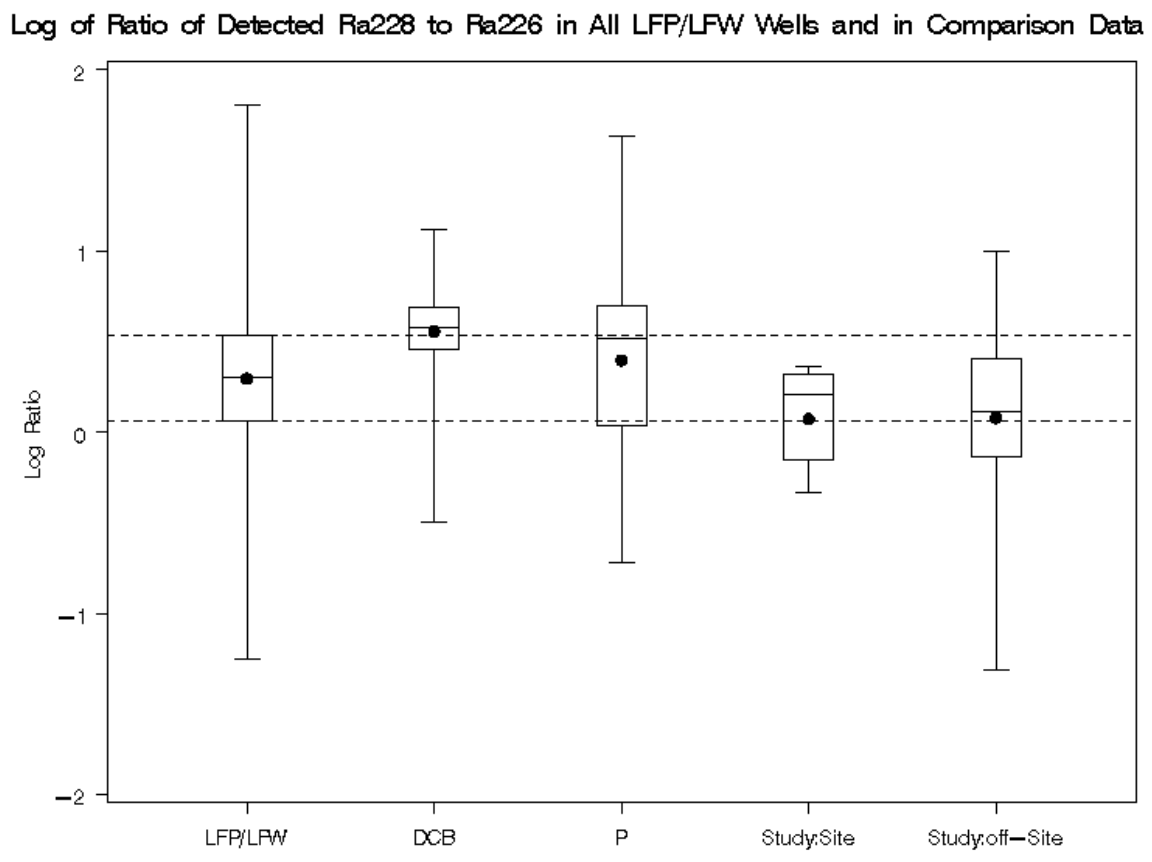

Figure 4: Comparison of the isotopic ratio of Ra228 to Ra226 concentrations in the SLF wells to these same ratios in the monitoring wells of four other facilities: three of which are on-Site (DCB, P, Study:Site) and one off-Site (Study:off-Site). 
Appendix B3 contains boxplots showing the relation of Ra226, Ra228, and gross alpha concentrations among the same five on- and off-Site locations. Again, the common logarithms are used, because the data on the original scale cross more than one order of magnitude. These plots also show reasonably equivalent concentrations of both radium isotopes and gross alpha in the SLF monitoring wells compared to well concentrations among the other on- and off-Site facilities known to be uncontaminated.

\subsection{Geochemical Analysis}

The following results were obtained based on expected geochemical relationships between inorganic constituents and water quality parameters versus isotopic radium and gross alpha.

\subsection{1. $\mathrm{pH}$ versus Radium and Gross Alpha}

Figure 5 shows plots of radium and gross alpha versus the field measurement of $\mathrm{pH}$ for quarterly samples among all SLF wells in this study. The plots suggest a quadratic (polynomial) relationship between Ra226 and $\mathrm{pH}$, between gross alpha and $\mathrm{pH}$, and possibly between $\mathrm{Ra} 228$ and $\mathrm{pH}$. In each plot, the quadratic relationship is statistically significant $(\mathrm{p}<.001)$. Note however, that there is no geochemical explanation for the polynomial fit. At the low $(<5) \mathrm{pH}$ range, an inverse correlation between radium level and $\mathrm{pH}$, i.e., increased radium mobility, is expected. Natural $\mathrm{pH}$ values at the SRS are rarely below 4.5. The low $\mathrm{pH}$ values may be from landfill leachate, and such leachate could mobilize natural aquifer radium. However, there is no geochemical explanation for reverse in this relationship at higher $\mathrm{pH}$ ranges. Other plots indicated no relationship between $\mathrm{pH}$ and a given well or set of well, nor is there any trend in $\mathrm{pH}$ with sampling date (quarters) across years. The polynomial could be a statistical artifact of the large number $(>2,700)$ of measurements in 16 years of sampling.

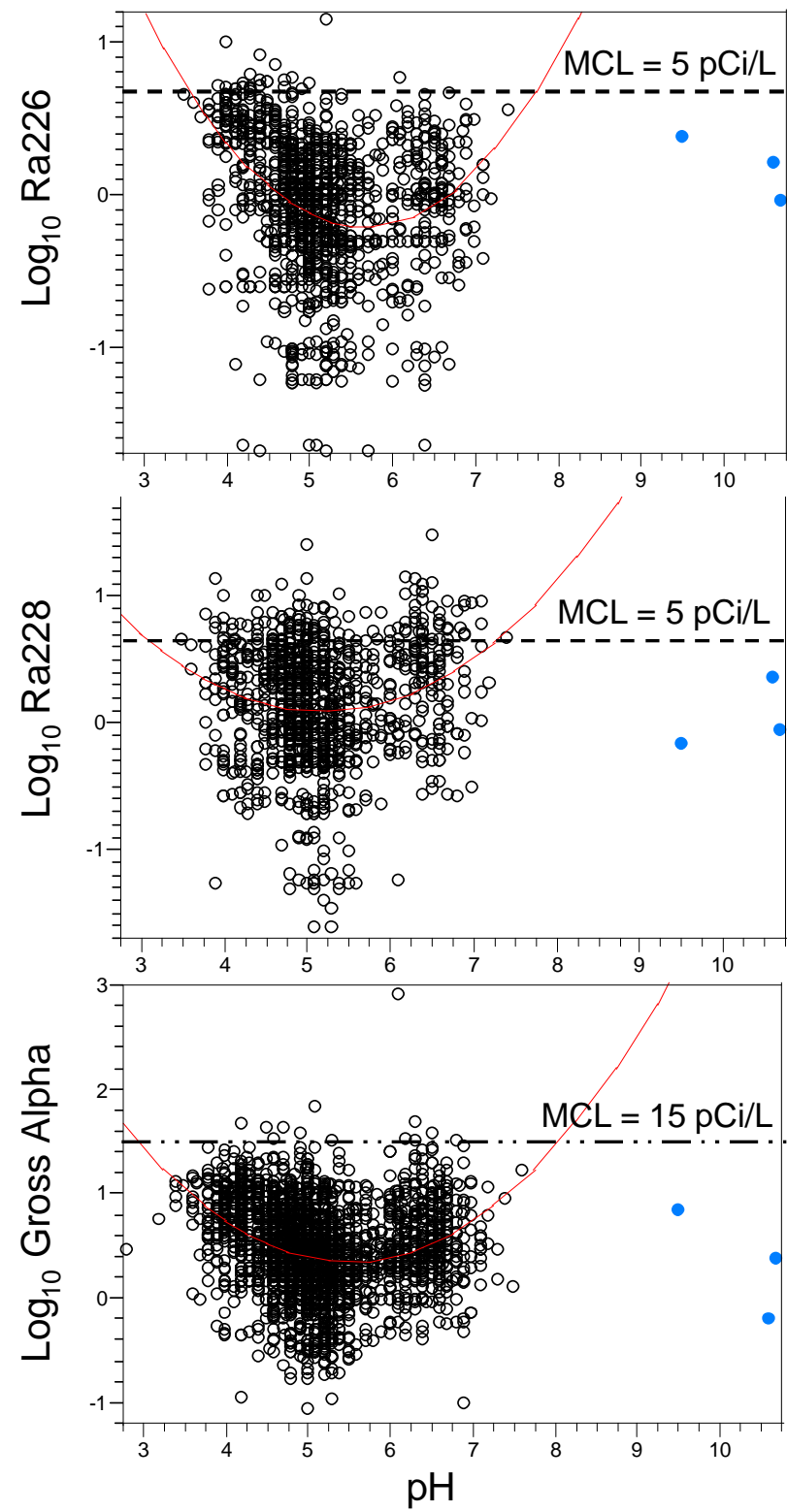

Figure 5. Scatter plots and quadratic linear regression fits of Ra226, Ra228, and gross alpha measurements vs $\mathrm{pH}$ from all wells and all years of the study - blue $\mathrm{pH}$ outliers excluded from regressions. 
The relatively small parameter estimation variances can yield statistically significant relationships with $\mathrm{pH}$, although the practical significance is in question as illustrated by the weak bivariate correlations seen here $(r=34, .20$, and .31 , respectively).

\subsubsection{Total Barium (BATOT) and Total Calcium (CATOT) versus Radium and Gross Alpha}

As indicated earlier, both $\mathrm{Ca}$ and $\mathrm{Ba}$ may behave geochemically as replacements for the $\mathrm{Ra}$ isotopes in the subsurface geology. Figures 6A and $6 \mathrm{~B}$ display plots of the BATOT and CATOT concentrations, respectively, versus Ra226 and ALPHAG for quarterly samples among all SLF wells. The patterns of Ra228 with these same metals are similar.

Note that the simple linear regression (SLR) fits (in red) in Figure 6A have statistically significant $(\mathrm{p}<.05)$ and positive slope, which means that as the concentration of $\mathrm{Ba}$ increases, $\mathrm{Ra} 226$ and gross alpha measurements also increase. The Orthogonal regression fits (in green) likewise show a positive relationship between $\mathrm{Ba}$ and $\mathrm{Ra} 226$ or gross alpha. Although the statistical relation for either radiological measurements is significant, the very low correlation (.10 and .14, respectively) indicates there is substantial unexplained variability in the SLR relationships.
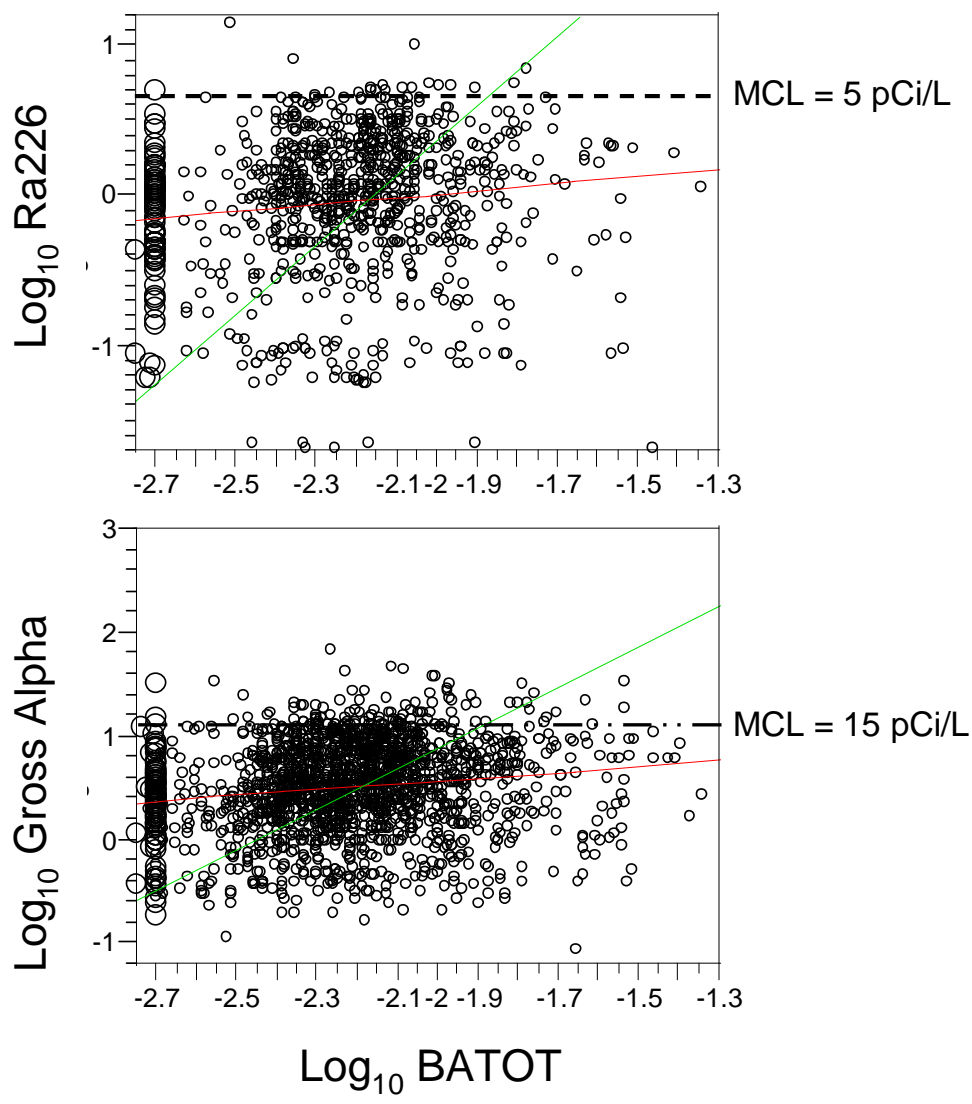

Figure 6A. Scatter plots and regressions fits for Ra226 and gross alpha concentrations $(\mathrm{pCi} / \mathrm{L})$ versus total Barium (BATOT) for all wells and all years, on the common log scale. The large symbols indicate BATOT values below detection that were excluded from regression fits.

Again, this is not unexpected geochemically because of the mass balance issues discussed in section 3.3.

Note also that vertical line of sample points at the -2.7 value of $\log$ BATOT (Figure 6A). This occurs because these data were recorded as laboratory measurements below detection. So regardless of the measured value for $\log$ Ra226, the measured value of $\log$ BATOT was the same. 
FINAL REPORT: Ra in the SLF WSRC-TR-2004-00141

Similarly, Figure 6B shows the SLR and Orthogonal regression fits to the same Ra226 and gross alpha data versus CATOT. The SLR has a statistically significant $(\mathrm{p}<.0001)$ and positive slope indicating that as total calcium concentration increases, so do Ra226 and gross alpha by a factor of .12 and .19 to 1 , respectively. There is a stronger positive correlation between CATOT and Ra226 or gross alpha (.19 and .26, respectively) than exists for BATOT. As noted before, the large amount of scatter or variability in these data is not unexpected because of accuracy and precision issues in mass balance calculations.

\subsubsection{Turbidity, Water Elevation, and Hold Times}

The scatter plots and linear regression analyses results for Ra226 or Ra228 versus turbidity and water elevation showed no statistically significant patterns or relationships. In addition, a review of the hold times for all samples prior to analysis indicated no excessive
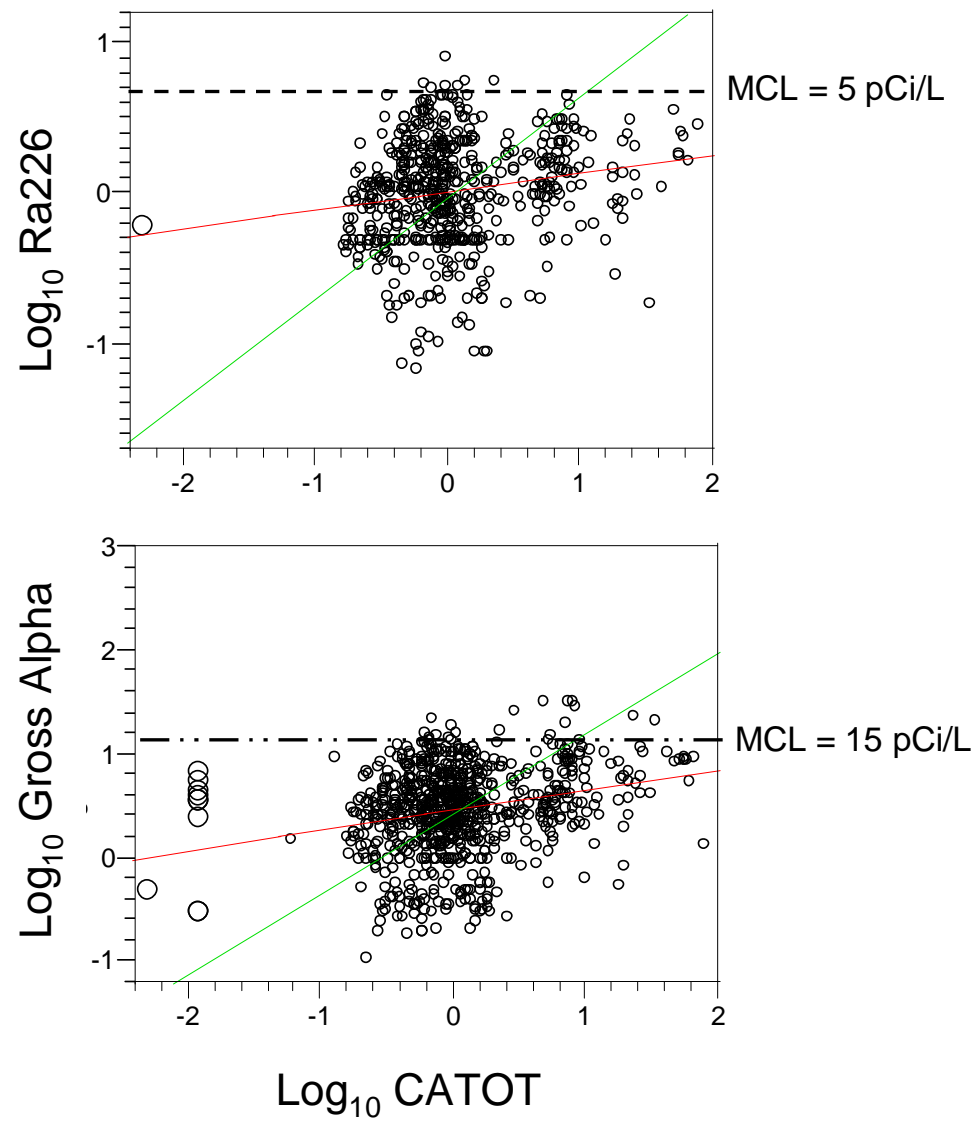

Figure 6B. Scatter plots and regressions fits for Ra226 and gross alpha concentrations $(\mathrm{pCi} / \mathrm{L})$ versus total Calcium (CATOT) for all wells and all years, on the common log scale. The large symbols indicate CATOT values below detection that were excluded from regression fits.

values. This suggests that elevated radium concentrations were not the result of variation in field sampling conditions or violations of laboratory analysis protocol.

\section{CONCLUSIONS}

The conclusion from this study is that there is insufficient evidence to reject the working hypothesis, viz., that the recent elevated measurements of Ra226, Ra228, or gross alpha are not from anthropogenic sources. In fact the evidence presented here suggests that radium in the SLF groundwater is not substantially different from the natural radium in the surrounding area. This does not eliminate the possibility that some natural radium was mobilized by the interaction of native soils with landfill leachate. 
FINAL REPORT: Ra in the SLF WSRC-TR-2004-00141

\section{REFERENCES}

WSRC (2003). Annual 2002 Sanitary Landfill Groundwater Monitoring Report (U), Savannah River Site, February 2003. Westinghouse Savannah River Company, LLC, Aiken, SC.

WSRC (1993). 1992 RCRA Part B Permit Renewal Application (U), (WSRC-IM-91-53) Savannah River Site, Volume XXIII, Book 1 through 4, Sanitary Landfill Postclosure, Rev. 1, March 1993. Westinghouse Savannah River Company, LLC, Aiken, SC.

WSRC (1995). Sanitary Landfill Groundwater Quality Assessment Plan - Amendment (U) (WSRC-RP-95-1538), Rev. 5, September 1995. Westinghouse Savannah River Company, LLC, Aiken, SC.

SAS (2000). SAS ${ }^{\circledast}$ Language: Reference. Version 8, First Edition. SAS Institute, Cary, NC.

JMP (2000). JMP ${ }^{\circledR}$ Statistics and Graphics Guide, Version 5. SAS Institute, Cary, NC.

Price, V. and J. Michel, 1990, "Radioactivity in Groundwater near the Savannah River Site (U)", WSRC-RP-89-267, Westinghouse Savannah River Company, Aiken SC.

Denham, M.E., D.M. Beals, and W.G. Winn, 1999, Radium in Groundwater Associated with a Coal Storage Pile, Abstracts with Program - Geological Society of America, v. 31, p. 13.

Noffsinger, D.C., April 2004, "Detection of Gross Alpha and Radium in Groundwater at the Sanitary Landfill: The Case for a Natural Source", ERD-EN-2004-0087. 


\section{APPENDIX A}

Appendix A contains summary information for the SLF wells used in this study and for the analyses performed for radioactive analytes in these wells.

\section{Appendix A1- Summary data for LFP/LFW wells used in this study of the SLF groundwater monitoring network}


FINAL REPORT: Ra in the SLF

WSRC-TR-2004-00141

\section{Sanitary Landfill Wells: LFP and LFW Well Series}

(Note: Ra2628 represents the sum of Ra226 and Ra228, and the level of concern is $5 \mathrm{pCi} / \mathrm{L}$ for radium and $15 \mathrm{pCi} / \mathrm{L}$ for gross alpha)

Well Well Type Install Date First Sampled Last Sampled Abandoned Elevation Level maxRA2628 maxRA226 maxRA228 maxALPHA

\begin{tabular}{|c|c|c|c|c|c|c|c|c|c|}
\hline & & & & & & $(\mathrm{pCi} / \mathrm{L})$ & $(\mathrm{pCi} / \mathrm{L})$ & $(\mathrm{pCi} / \mathrm{L})$ & $(\mathrm{pCi} / \mathrm{L})$ \\
\hline LFP 1WP & MONITORING WELL & 04/05/1994 & 06/27/2001 & 07/01/2002 & no elevation & 2.35 & 2.35 & & 1.55 \\
\hline LFP 2WP & MONITORING WELL & 04/06/1994 & $06 / 28 / 2001$ & $07 / 01 / 2002$ & no elevation & 0.2335 & 0.2335 & & 1.27 \\
\hline LFP $3 W P$ & MONITORING WELL & 04/06/1994 & 05/01/2002 & 05/01/2002 & no data & & & & \\
\hline LFP 5WP & MONITORING WELL & 04/08/1994 & $06 / 25 / 2001$ & $12 / 02 / 2003$ & RA recent & 9.19 & 5.92 & 5.82 & 839 \\
\hline LFP 6WP & MONITORING WELL & 04/08/1994 & 06/26/2001 & $11 / 21 / 2003$ & RA recent & 14.352 & 2.31 & 14 & 26.3 \\
\hline LFP 7WP & MONITORING WELL & 04/08/1994 & 05/02/2002 & 05/02/2002 & no data & & & & \\
\hline LFP 9WP & MONITORING WELL & 04/05/1994 & $05 / 14 / 2002$ & $05 / 14 / 2002$ & no data & & & & \\
\hline LFP 10WP & MONITORING WELL & 04/04/1994 & $06 / 21 / 2001$ & 06/28/2002 & no elevation & 0.851 & 0.851 & & 1.75 \\
\hline LFP 11WP & MONITORING WELL & 04/06/1994 & 06/20/2001 & $11 / 21 / 2003$ & no elevation & 1.71 & 0.78 & 0.966 & 2.38 \\
\hline LFP 12WP & MONITORING WELL & 04/07/1994 & $06 / 12 / 2001$ & $11 / 21 / 2003$ & no elevation & 2.6 & 2.01 & 0.936 & 3.33 \\
\hline LFP 13WP & MONITORING WELL & 04/07/1994 & $06 / 28 / 2001$ & $11 / 21 / 2003$ & RA recent & 55.56 & 1.67 & 54.7 & 2.44 \\
\hline LFP 14WP & MONITORING WELL & 04/07/1994 & 06/26/2001 & $12 / 01 / 2003$ & no elevation & 1.665 & 0.585 & 1.08 & 3.445 \\
\hline LFW 1 & & & & & $11 / 24 / 1986$ no data & & & & \\
\hline LFW 2 & & & & & $12 / 05 / 1986$ no data & & & & \\
\hline LFW 3 & & & & & $12 / 04 / 1986$ no data & & & & \\
\hline LFW 5 & & & & & 12/01/1986 no data & & & & \\
\hline LFW 6 & MONITORING WELL & $02 / 02 / 1981$ & $07 / 17 / 1984$ & 02/07/1996 & 02/26/1996 RA old & 12.6 & 4.26 & 10.9 & 18 \\
\hline LFW $6 \mathrm{R}$ & MONITORING WELL & 03/12/1996 & 06/25/1996 & $10 / 27 / 2003$ & ALPHAG only & 4.21 & 1.62 & 3.17 & 34.5 \\
\hline LFW 7 & MONITORING WELL & 01/30/1981 & $07 / 17 / 1984$ & 09/06/1995 & 02/26/1996 RA old & 33 & 2.1 & 30.9 & 28.6 \\
\hline LFW 8 & MONITORING WELL & 01/29/1981 & $07 / 17 / 1984$ & 02/08/1996 & 02/26/1996 RA old & 15.74 & 4 & 11.9 & 34.6 \\
\hline LFW 8R & MONITORING WELL & 03/12/1996 & 06/25/1996 & $10 / 30 / 2003$ & RA recent & 15.62 & 4.52 & 11.1 & 27.3 \\
\hline LFW 9 & MONITORING WELL & $01 / 28 / 1981$ & 07/18/1984 & $10 / 02 / 1986$ & $11 / 26 / 1986$ no data & & & & \\
\hline LFW 10 & & & & & $01 / 01 / 1984$ no data & & & & \\
\hline LFW 10A & MONITORING WELL & $01 / 13 / 1984$ & 07/19/1984 & $10 / 27 / 2003$ & RA old & 8.3 & 4.7 & 6.6 & 25 \\
\hline
\end{tabular}


FINAL REPORT: Ra in the SLF WSRC-TR-2004-00141

Well Well Type Install Date First Sampled Last Sampled Abandoned Elevation Level maxRA2628 maxRA226 maxRA228 maxALPHAG

\begin{tabular}{|c|c|c|c|c|c|c|c|c|c|}
\hline & & & & & & $(\mathrm{pCi} / \mathrm{L})$ & $(\mathrm{pCi} / \mathrm{L})$ & $(\mathrm{pCi} / \mathrm{L})$ & $(\mathrm{pCi} / \mathrm{L})$ \\
\hline LFW 16 & MONITORING WELL & $08 / 26 / 1981$ & $07 / 18 / 1984$ & $03 / 01 / 1995$ & 02/28/1996 RA old & 6.3 & 1.5 & 5 & 12 \\
\hline LFW 17 & MONITORING WELL & 08/28/1981 & 07/18/1984 & $12 / 15 / 1995$ & 02/28/1996 RA old & 13.23 & 2.94 & 12.6 & 4.49 \\
\hline LFW 18 & MONITORING WELL & $08 / 27 / 1981$ & $07 / 18 / 1984$ & $10 / 27 / 2003$ & RA recent & 17.62 & 4.34 & 14.6 & 39.5 \\
\hline LFW 19 & MONITORING WELL & $08 / 31 / 1981$ & $07 / 18 / 1984$ & $12 / 16 / 1995$ & 02/26/1996 RA old & 9.3 & 2.7 & 8 & 10 \\
\hline LFW 20 & MONITORING WELL & 08/25/1981 & 07/19/1984 & $12 / 08 / 1995$ & RA old & 7.6 & 2.71 & 6 & 8.8 \\
\hline LFW 21 & MONITORING WELL & $01 / 11 / 1984$ & 07/19/1984 & $10 / 27 / 2003$ & RA old & 10.7 & 4.2 & 6.5 & 35 \\
\hline LFW 22 & MONITORING WELL & $01 / 12 / 1984$ & 07/19/1984 & $12 / 18 / 1995$ & 02/27/1996 RA old & 5.4 & 2.5 & 3 & 22.2 \\
\hline LFW 23 & MONITORING WELL & $01 / 12 / 1984$ & 07/19/1984 & 02/06/1996 & 02/28/1996 RA old & 5.15 & 1.8 & 3.48 & 7.5 \\
\hline LFW 23R & MONITORING WELL & 03/06/1996 & 06/17/1996 & $10 / 22 / 2003$ & RA recent & 15.03 & 7.4 & 7.96 & 47.8 \\
\hline LFW 24 & MONITORING WELL & $01 / 13 / 1984$ & 07/23/1984 & $12 / 13 / 1995$ & 02/28/1996 RA old & 5.7 & 1.84 & 4.4 & 7.6 \\
\hline LFW 25 & MONITORING WELL & $01 / 13 / 1984$ & $07 / 23 / 1984$ & $12 / 13 / 1995$ & 02/28/1996 RA old & 11.2 & 2.2 & 10 & 14 \\
\hline LFW 26 & MONITORING WELL & 10/29/1986 & $02 / 05 / 1987$ & $12 / 08 / 1995$ & RA old & 5.62 & 1.56 & 5 & 9.58 \\
\hline LFW 27 & MONITORING WELL & $10 / 30 / 1986$ & $02 / 05 / 1987$ & $12 / 08 / 1995$ & no elevation & 4.29 & 1.19 & 3.7 & 4 \\
\hline LFW 28 & MONITORING WELL & $10 / 28 / 1986$ & $02 / 05 / 1987$ & $11 / 18 / 2003$ & RA old & 6.9 & 2.2 & 5.7 & 6.68 \\
\hline LFW 29 & MONITORING WELL & $10 / 28 / 1986$ & $02 / 05 / 1987$ & $10 / 23 / 2003$ & RA recent & 7.67 & 3.27 & 5.3 & 9.5 \\
\hline LFW 30 & MONITORING WELL & $12 / 31 / 1986$ & 02/06/1987 & $11 / 18 / 2003$ & RA old & 6.43 & 0.98 & 5.5 & 7.5 \\
\hline LFW 32 & MONITORING WELL & $10 / 24 / 1986$ & $02 / 05 / 1987$ & $12 / 02 / 2003$ & RA old & 11.5 & 3.3 & 8.2 & 14.3 \\
\hline LFW 32C & MONITORING WELL & $12 / 05 / 1997$ & 02/06/1998 & $11 / 18 / 2003$ & no elevation & & & & 3.015 \\
\hline LFW 33 & MONITORING WELL & 10/23/1986 & $02 / 05 / 1987$ & 04/22/1996 & RA old & 27 & 3.27 & 26 & 16.2 \\
\hline LFW 34 & MONITORING WELL & $10 / 22 / 1986$ & $02 / 05 / 1987$ & $11 / 18 / 2003$ & RA old & 6.39 & 1.8 & 4.99 & 18.3 \\
\hline LFW 35 & MONITORING WELL & $10 / 21 / 1986$ & $02 / 05 / 1987$ & $12 / 08 / 1995$ & RA old & 6.1 & 1.8 & 4.4 & 7.3 \\
\hline LFW 36 & MONITORING WELL & $11 / 05 / 1986$ & $02 / 05 / 1987$ & $12 / 16 / 1995$ & 02/26/1996 RA old & 14.49 & 2.99 & 11.5 & 32.9 \\
\hline LFW 36R & MONITORING WELL & 03/08/1996 & 06/25/1996 & $10 / 24 / 2003$ & RA recent & 7.8 & 2.7 & 6.71 & 35.1 \\
\hline LFW 37 & MONITORING WELL & $11 / 04 / 1986$ & 02/06/1987 & $12 / 16 / 1995$ & 02/26/1996 RA old & 10.5 & 4.22 & 8.5 & 24.2 \\
\hline LFW 38 & MONITORING WELL & $11 / 03 / 1986$ & 02/06/1987 & 03/03/1995 & 02/26/1996 ALPHAG only & 4.8 & 1.5 & 3.7 & 7 \\
\hline LFW 39 & MONITORING WELL & $11 / 03 / 1986$ & 02/06/1987 & 03/03/1995 & 02/27/1996 RA old & 8.1 & 3.4 & 4.7 & 32.8 \\
\hline LFW 40 & MONITORING WELL & $10 / 31 / 1986$ & $02 / 06 / 1987$ & 03/03/1995 & 02/27/1996 RA old & 7.85 & 3.2 & 6.9 & 21.7 \\
\hline LFW 41 & MONITORING WELL & $10 / 31 / 1986$ & 02/06/1987 & 02/06/1996 & 02/27/1996 RA old & 8.16 & 1.58 & 7.2 & 4 \\
\hline LFW 41R & MONITORING WELL & 03/06/1996 & 06/17/1996 & $10 / 22 / 2003$ & RA recent & 6.52 & 4.84 & 4.82 & 19.6 \\
\hline LFW 42 & MONITORING WELL & $10 / 30 / 1986$ & 02/06/1987 & 03/03/1995 & 02/27/1996 ALPHAG only & 3.9 & 1.2 & 2.8 & 8.7 \\
\hline LFW 43B & MONITORING WELL & $06 / 21 / 1991$ & 09/02/1991 & $11 / 18 / 2003$ & RA old & 6.13 & 3.01 & 5.18 & 21.6 \\
\hline LFW 43C & MONITORING WELL & 06/25/1991 & 09/02/1991 & $11 / 18 / 2003$ & RA old & 8.09 & 2.23 & 7.26 & 13.13 \\
\hline
\end{tabular}


FINAL REPORT: Ra in the SLF WSRC-TR-2004-00141

Well Well Type Install Date First Sampled Last Sampled Abandoned Elevation Level maxRA2628 maxRA226 maxRA228 maxALPHAG

\begin{tabular}{|c|c|c|c|c|c|c|c|c|c|}
\hline & & & & & & $(\mathrm{pCi} / \mathrm{L})$ & $(\mathrm{pCi} / \mathrm{L})$ & $(\mathrm{pCi} / \mathrm{L})$ & $(\mathrm{pCi} / \mathrm{L})$ \\
\hline LFW 43D & MONITORING WELL & $06 / 24 / 1991$ & $09 / 02 / 1991$ & $11 / 18 / 2003$ & RA old & 6.94 & 1.23 & 6.2 & 12.93 \\
\hline LFW 44D & MONITORING WELL & 05/29/1991 & 09/02/1991 & $11 / 18 / 2003$ & RA old & 6.83 & 3.03 & 5.65 & 9.2 \\
\hline LFW 45D & MONITORING WELL & 05/16/1991 & 09/02/1991 & $10 / 30 / 2003$ & RA recent & 8.65 & 3.35 & 5.3 & 32.2 \\
\hline LFW 46D & MONITORING WELL & 05/29/1991 & 09/02/1991 & $12 / 04 / 1995$ & RA old & 6.5 & 2.7 & 5 & 11.6 \\
\hline LFW 47C & MONITORING WELL & 05/29/1991 & 09/02/1991 & $10 / 30 / 2003$ & RA recent & 12.44 & 6.39 & 6.05 & 28.5 \\
\hline LFW 47D & MONITORING WELL & 05/23/1991 & 09/02/1991 & $10 / 30 / 2003$ & ALPHAG only & 4.935 & 1.73 & 4.8 & 22.5 \\
\hline LFW 48C & MONITORING WELL & 05/28/1991 & 09/02/1991 & $10 / 23 / 2003$ & no elevation & 3.2315 & 2.16 & 2.7 & 4.035 \\
\hline LFW 48D & MONITORING WELL & 05/23/1991 & 09/02/1991 & $10 / 23 / 2003$ & RA old & 14.14 & 3.54 & 10.6 & 13.2 \\
\hline LFW 55C & MONITORING WELL & 05/14/1991 & 09/03/1991 & $12 / 05 / 1995$ & RA old & 6 & 2.05 & 5 & 5.45 \\
\hline LFW 55D & MONITORING WELL & 05/15/1991 & 09/03/1991 & $12 / 05 / 1995$ & RA old & 6.24 & 2.68 & 3.6 & 4.48 \\
\hline LFW 56D & MONITORING WELL & 05/22/1991 & 09/03/1991 & $10 / 29 / 2003$ & ALPHAG only & 4.814 & 4.36 & 2.8 & 44.7 \\
\hline LFW 57B & MONITORING WELL & $06 / 11 / 1991$ & 09/03/1991 & $01 / 23 / 2004$ & RA recent & 18.7 & 8.4 & 10.3 & 27.1 \\
\hline LFW 57C & MONITORING WELL & $05 / 21 / 1991$ & 09/03/1991 & $10 / 24 / 2003$ & RA old & 6.05 & 4.77 & 4.3 & 7.1 \\
\hline LFW 57D & MONITORING WELL & 05/21/1991 & 09/03/1991 & $10 / 24 / 2003$ & ALPHAG only & 4.58 & 1.05 & 3.89 & 5.3 \\
\hline LFW 58D & MONITORING WELL & $05 / 21 / 1991$ & 09/03/1991 & $10 / 29 / 2003$ & RA old & 8.41 & 2.39 & 7.7 & 11.41 \\
\hline LFW 59B & MONITORING WELL & 06/13/1991 & 09/04/1991 & $07 / 17 / 2001$ & RA old & 10.6 & 4.2 & 6.4 & 13.4 \\
\hline LFW 59D & MONITORING WELL & 06/18/1991 & 09/04/1991 & $10 / 27 / 2003$ & ALPHAG only & 4.29 & 2.03 & 3.5 & 22.9 \\
\hline LFW 60B & MONITORING WELL & $12 / 10 / 1993$ & 03/27/1994 & $12 / 08 / 1995$ & RA old & 6.92 & 4.54 & 2.5 & 8.68 \\
\hline LFW 60C & MONITORING WELL & $12 / 14 / 1993$ & 03/21/1994 & $10 / 24 / 2003$ & ALPHAG only & 4.4135 & 3.96 & 1.6 & 25.4 \\
\hline LFW 60D & MONITORING WELL & 06/18/1991 & 09/05/1991 & $10 / 24 / 2003$ & ALPHAG only & 2.35 & 0.95 & 2.1 & 24.8 \\
\hline LFW 61C & MONITORING WELL & 05/20/1991 & 09/04/1991 & $10 / 27 / 2003$ & no elevation & 4.19 & 1.4 & 3.6 & 4.49 \\
\hline LFW 61D & MONITORING WELL & 05/20/1991 & 09/04/1991 & $10 / 29 / 2003$ & RA old & 7.2 & 2.5 & 5.1 & 31 \\
\hline LFW 62B & MONITORING WELL & 06/11/1991 & 09/04/1991 & $01 / 23 / 2004$ & RA recent & 19.18 & 5.28 & 13.9 & 19.5 \\
\hline LFW 62C & MONITORING WELL & $06 / 11 / 1991$ & 09/04/1991 & $01 / 28 / 2004$ & RA old & 5.8 & 2.27 & 4.3 & 6.18 \\
\hline LFW 62D & MONITORING WELL & 06/05/1991 & 09/05/1991 & $01 / 23 / 2004$ & ALPHAG only & 3.777 & 1.22 & 2.94 & 13.4 \\
\hline LFW 63B & MONITORING WELL & $01 / 11 / 1994$ & 03/29/1994 & $10 / 29 / 2002$ & RA old & 8.04 & 5.39 & 4.29 & 20 \\
\hline LFW 63C & MONITORING WELL & $01 / 11 / 1994$ & 03/29/1994 & $07 / 17 / 2003$ & RA old & 8.01 & 2.24 & 7.5 & 12.1 \\
\hline LFW 63D & MONITORING WELL & $01 / 11 / 1994$ & 03/29/1994 & $10 / 24 / 2003$ & no elevation & 3.701 & 2.79 & 3.6 & 13.11 \\
\hline LFW 64B & MONITORING WELL & 02/01/1994 & $04 / 05 / 1994$ & $11 / 02 / 2002$ & RA old & 8.8 & 3.8 & 6.4 & 13.3 \\
\hline LFW 64C & MONITORING WELL & 02/02/1994 & 03/27/1994 & $10 / 30 / 2003$ & RA recent & 13.7 & 10.6 & 5.5 & 47.1 \\
\hline LFW 64D & MONITORING WELL & 02/02/1994 & 03/27/1994 & $10 / 29 / 2003$ & no elevation & 3.84 & 1.31 & 2.54 & 11.61 \\
\hline LFW 65B & MONITORING WELL & $12 / 23 / 1993$ & 03/25/1994 & $10 / 29 / 2002$ & RA old & 6.63 & 5.6 & 3.31 & 14.13 \\
\hline
\end{tabular}


FINAL REPORT: Ra in the SLF WSRC-TR-2004-00141

Well Well Type Install Date First Sampled Last Sampled Abandoned Elevation Level maxRA2628 maxRA226 maxRA228 maxALPHAG

\begin{tabular}{|c|c|c|c|c|c|c|c|c|c|}
\hline & & & & & & $(\mathrm{pCi} / \mathrm{L})$ & $(\mathrm{pCi} / \mathrm{L})$ & $(\mathrm{pCi} / \mathrm{L})$ & $(\mathrm{pCi} / \mathrm{L})$ \\
\hline LFW 65C & MONITORING WELL & $01 / 03 / 1994$ & 03/27/1994 & $10 / 30 / 2003$ & ALPHAG only & 4.16 & 2.19 & 2.7 & 12.48 \\
\hline LFW 65D & MONITORING WELL & 01/04/1994 & 04/05/1994 & $10 / 30 / 2003$ & ALPHAG only & 4.495 & 0.92 & 3.93 & 17.1 \\
\hline LFW 66B & MONITORING WELL & $12 / 21 / 1993$ & 03/26/1994 & $04 / 08 / 2003$ & 11/20/2003 RA recent & 5.1 & 2.73 & 2.73 & 50.4 \\
\hline LFW 66C & MONITORING WELL & $12 / 21 / 1993$ & 03/26/1994 & $07 / 22 / 2003$ & 08/20/2003 ALPHAG only & 3.99 & 2.45 & 2.37 & 9.1 \\
\hline LFW 66CR & MONITORING WELL & 08/19/2003 & $11 / 14 / 2003$ & $11 / 14 / 2003$ & no elevation & 2.095 & 1.3 & 0.795 & 2.575 \\
\hline LFW 66D & MONITORING WELL & $12 / 21 / 1993$ & 03/26/1994 & $11 / 01 / 2003$ & no elevation & 3.22 & 0.914 & 2.5 & 3.905 \\
\hline LFW 67B & MONITORING WELL & $01 / 24 / 1994$ & 03/28/1994 & $10 / 30 / 2003$ & RA recent & 7.78 & 4.11 & 4.68 & 44.1 \\
\hline LFW 67C & MONITORING WELL & 01/26/1994 & 03/28/1994 & $10 / 30 / 2003$ & RA old & 6.12 & 4.77 & 2.71 & 13.56 \\
\hline LFW 67D & MONITORING WELL & 01/26/1994 & 03/28/1994 & $10 / 30 / 2003$ & RA old & 7.97 & 5.52 & 3.41 & 69.1 \\
\hline LFW 68B & MONITORING WELL & 01/18/1994 & 03/28/1994 & $12 / 08 / 1995$ & RA old & 5.9 & 4.61 & 3.1 & 16.9 \\
\hline LFW 68C & MONITORING WELL & $01 / 14 / 1994$ & 03/28/1994 & $11 / 01 / 2003$ & RA old & 8.73 & 5.01 & 3.72 & 13.43 \\
\hline LFW 68D & MONITORING WELL & $01 / 18 / 1994$ & 03/28/1994 & $11 / 01 / 2003$ & RA old & 28.7835 & 28.3 & 6.51 & 12.81 \\
\hline LFW 69B & MONITORING WELL & 02/07/1994 & 03/26/1994 & $12 / 07 / 1995$ & RA old & 15.2 & 3.8 & 11.7 & 11.9 \\
\hline LFW 69C & MONITORING WELL & 02/08/1994 & 03/26/1994 & $10 / 30 / 2003$ & RA recent & 8.53 & 5.89 & 4.52 & 16 \\
\hline LFW 69D & MONITORING WELL & 02/07/1994 & 03/26/1994 & $10 / 30 / 2003$ & no elevation & 3.94 & 3.21 & 3.6 & 12.39 \\
\hline LFW 70B & MONITORING WELL & 02/17/1994 & 03/20/1994 & $12 / 07 / 1995$ & RA old & 6.06 & 5.8 & 2.8 & 10.2 \\
\hline LFW 70D & MONITORING WELL & 02/16/1994 & 03/20/1994 & $10 / 31 / 2002$ & no elevation & 1.38 & 0.38 & 1 & 1.17 \\
\hline LFW 71B & MONITORING WELL & 02/11/1994 & 03/29/1994 & $10 / 31 / 2002$ & RA old & 7.6 & 3.6 & 4 & 20.5 \\
\hline LFW 71C & MONITORING WELL & $02 / 11 / 1994$ & 04/05/1994 & $10 / 30 / 2003$ & RA old & 6 & 3.33 & 3.1 & 13.11 \\
\hline LFW 71D & MONITORING WELL & 02/11/1994 & 03/29/1994 & $10 / 30 / 2003$ & ALPHAG only & 2.621 & 0.952 & 2.05 & 11.68 \\
\hline LFW 72B & MONITORING WELL & 02/22/1994 & 03/29/1994 & $12 / 06 / 1995$ & RA old & 8.46 & 5.17 & 3.54 & 18.5 \\
\hline LFW 72C & MONITORING WELL & 02/22/1994 & 03/29/1994 & $12 / 06 / 1995$ & RA old & 7.84 & 2.54 & 5.3 & 2.9 \\
\hline LFW 72D & MONITORING WELL & $02 / 21 / 1994$ & 03/29/1994 & $12 / 06 / 1995$ & no elevation & 3.77 & 0.87 & 2.9 & 3.6 \\
\hline LFW 73C & MONITORING WELL & 04/29/1994 & $12 / 12 / 2001$ & $11 / 01 / 2002$ & no data & & & & \\
\hline LFW 74C & MONITORING WELL & $11 / 18 / 1994$ & 03/17/1995 & $12 / 02 / 2003$ & no elevation & & & & 2.59 \\
\hline LFW 74D & MONITORING WELL & $11 / 18 / 1994$ & 03/17/1995 & $11 / 18 / 2003$ & no elevation & & & & 2.465 \\
\hline LFW 75C & MONITORING WELL & $11 / 28 / 1994$ & 03/17/1995 & $11 / 18 / 2003$ & no elevation & & & & 3.46 \\
\hline LFW 75D & MONITORING WELL & $11 / 21 / 1994$ & 03/17/1995 & $12 / 02 / 2003$ & no elevation & & & & 4.4 \\
\hline LFW 76 & MONITORING WELL & $12 / 04 / 1997$ & $02 / 17 / 1998$ & $04 / 14 / 2003$ & no elevation & & & & 2.43 \\
\hline LFW 77 & MONITORING WELL & $12 / 07 / 1997$ & 02/06/1998 & 08/10/1998 & no data & & & & \\
\hline LFW 78 & MONITORING WELL & $12 / 03 / 1997$ & $02 / 17 / 1998$ & $04 / 14 / 2003$ & no data & & & & \\
\hline
\end{tabular}


FINAL REPORT: Ra in the SLF WSRC-TR-2004-00141

recent (2003 on) elevated Ra2628

older (prior to 2003) elevated Ra2628

elevated gross alpha only 


\section{Appendix A2- Analyses performed for radioactive analytes in the SLF wells}


FINAL REPORT: Ra in the SLF WSRC-TR-2004-00141

\begin{tabular}{|c|c|c|c|c|c|c|}
\hline analyte & \# analyses & \# detects & $\%$ detect & max detect & min detect & units \\
\hline ALPHAG & 3555 & 2431 & $68 \%$ & 839 & 0.1 & $\mathrm{pCi} / \mathrm{L}$ \\
\hline RA226 & 1581 & 1255 & $79 \%$ & 28.3 & 0.09 & $\mathrm{pCi} / \mathrm{L}$ \\
\hline RA228 & 1462 & 999 & $68 \%$ & 54.7 & 0.1 & $\mathrm{pCi} / \mathrm{L}$ \\
\hline BETAG & 2302 & 1727 & $75 \%$ & 140.6 & 0.33 & $\mathrm{pCi} / \mathrm{L}$ \\
\hline NP237 & 10 & 1 & $10 \%$ & 0.317 & 0.317 & $\mathrm{pCi} / \mathrm{L}$ \\
\hline TH228 & 10 & 2 & $20 \%$ & 1.33 & 0.493 & $\mathrm{pCi} / \mathrm{L}$ \\
\hline TH232 & 10 & 4 & $40 \%$ & 0.328 & 0.116 & $\mathrm{pCi} / \mathrm{L}$ \\
\hline TOTACT & 135 & 94 & $70 \%$ & 66.6 & 1.03 & $\mathrm{pCi} / \mathrm{L}$ \\
\hline TOTRAD & 840 & 658 & $78 \%$ & 63.7 & 0.2 & $\mathrm{pCi} / \mathrm{L}$ \\
\hline TRITIU & 3799 & 3288 & $87 \%$ & 1120.83 & 0.00084 & $\mathrm{pCi} / \mathrm{mL}$ \\
\hline U238 & 11 & 2 & $18 \%$ & 0.455 & 0.128 & $\mathrm{pCi} / \mathrm{L}$ \\
\hline U3334 & 11 & 1 & $9 \%$ & 0.369 & 0.369 & $\mathrm{pCi} / \mathrm{L}$ \\
\hline AC228 & 1 & 0 & & & & \\
\hline AM241 & 10 & 0 & & & & \\
\hline BA133 & 1 & 0 & & & & \\
\hline CE144 & 1 & 0 & & & & \\
\hline CM242 & 10 & 0 & & & & \\
\hline CM4344 & 10 & 0 & & & & \\
\hline CM4546 & 6 & 0 & & & & \\
\hline CO57 & 1 & 0 & & & & \\
\hline CO58 & 1 & 0 & & & & \\
\hline CO60 & 1 & 0 & & & & \\
\hline CS134 & 1 & 0 & & & & \\
\hline CS137 & 1 & 0 & & & & \\
\hline EU152 & 1 & 0 & & & & \\
\hline EU154 & 1 & 0 & & & & \\
\hline EU155 & 1 & 0 & & & & \\
\hline $\mathrm{K} 40$ & 1 & 0 & & & & \\
\hline MN54 & 1 & 0 & & & & \\
\hline NA22 & 1 & 0 & & & & \\
\hline NP239 & 1 & 0 & & & & \\
\hline PB212 & 1 & 0 & & & & \\
\hline PM144 & 1 & 0 & & & & \\
\hline PM146 & 1 & 0 & & & & \\
\hline PU238 & 10 & 0 & & & & \\
\hline PU3940 & 10 & 0 & & & & \\
\hline RU106 & 1 & 0 & & & & \\
\hline SB124 & 1 & 0 & & & & \\
\hline SB125 & 1 & 0 & & & & \\
\hline SN113 & 1 & 0 & & & & \\
\hline TH230 & 2 & 0 & & & & \\
\hline TH234 & 1 & 0 & & & & \\
\hline U235 & 11 & 0 & & & & \\
\hline Y88 & 1 & 0 & & & & \\
\hline ZN65 & 1 & 0 & & & & \\
\hline ZR95 & 1 & 0 & & & & \\
\hline
\end{tabular}


FINAL REPORT: Ra in the SLF WSRC-TR-2004-00141

\section{APPENDIX B}

Appendix B contains three sets of plots: time plots by well, time plots by analyte, and comparative boxplots.

\section{Appendix B1 - Time series plots by well}


FINAL REPORT: Ra in the SLF WSRC-TR-2004-00141

SLF Wells (LFW, LFP Series): Recent Elevated Radium

(Note: Gross Alpha Outlier Triggers Different Scale)

WELL= LFP 5WP

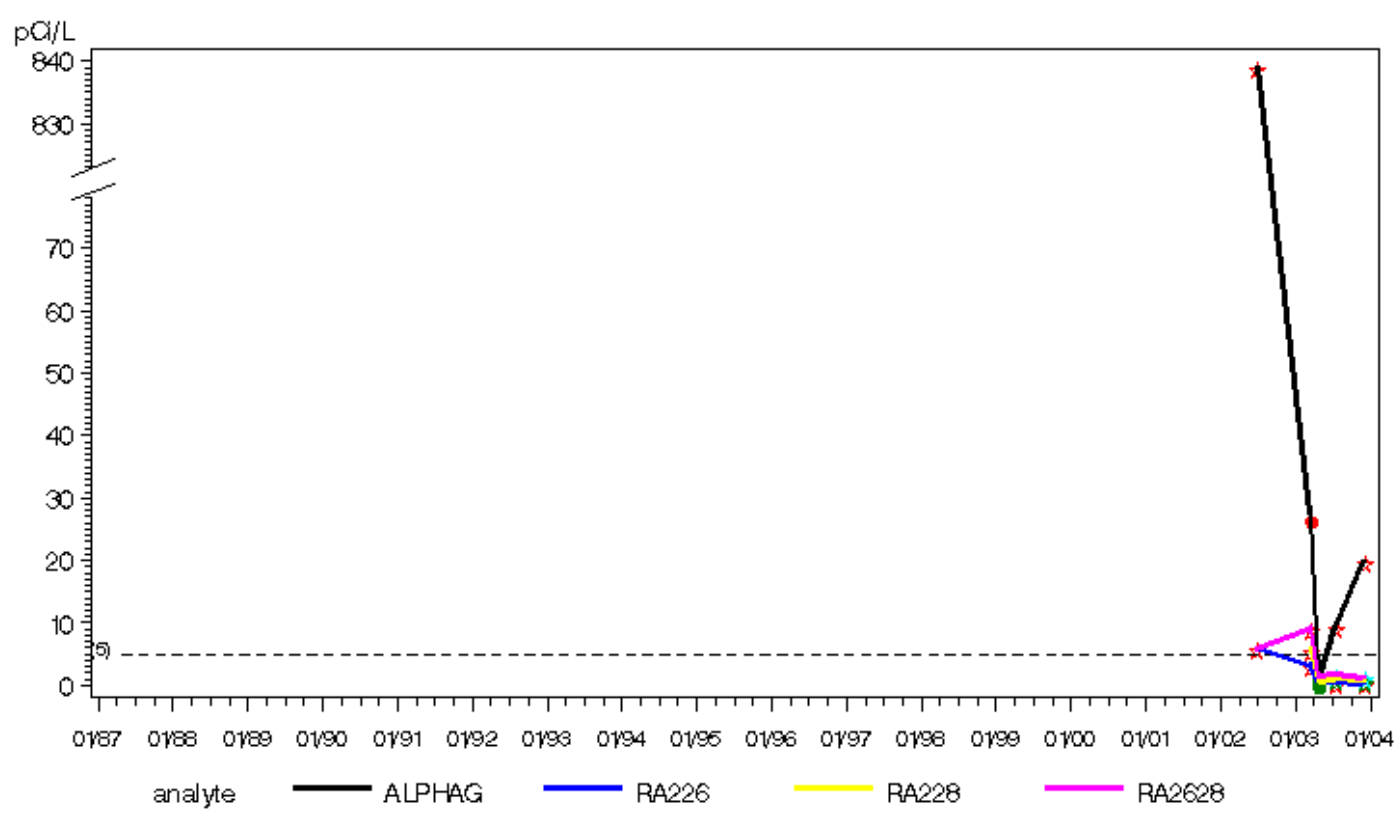

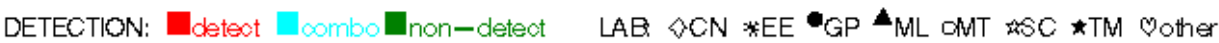

SLF Wells (LFW, IFP Series): Recent Elevated Radium WELL=LFP GWP

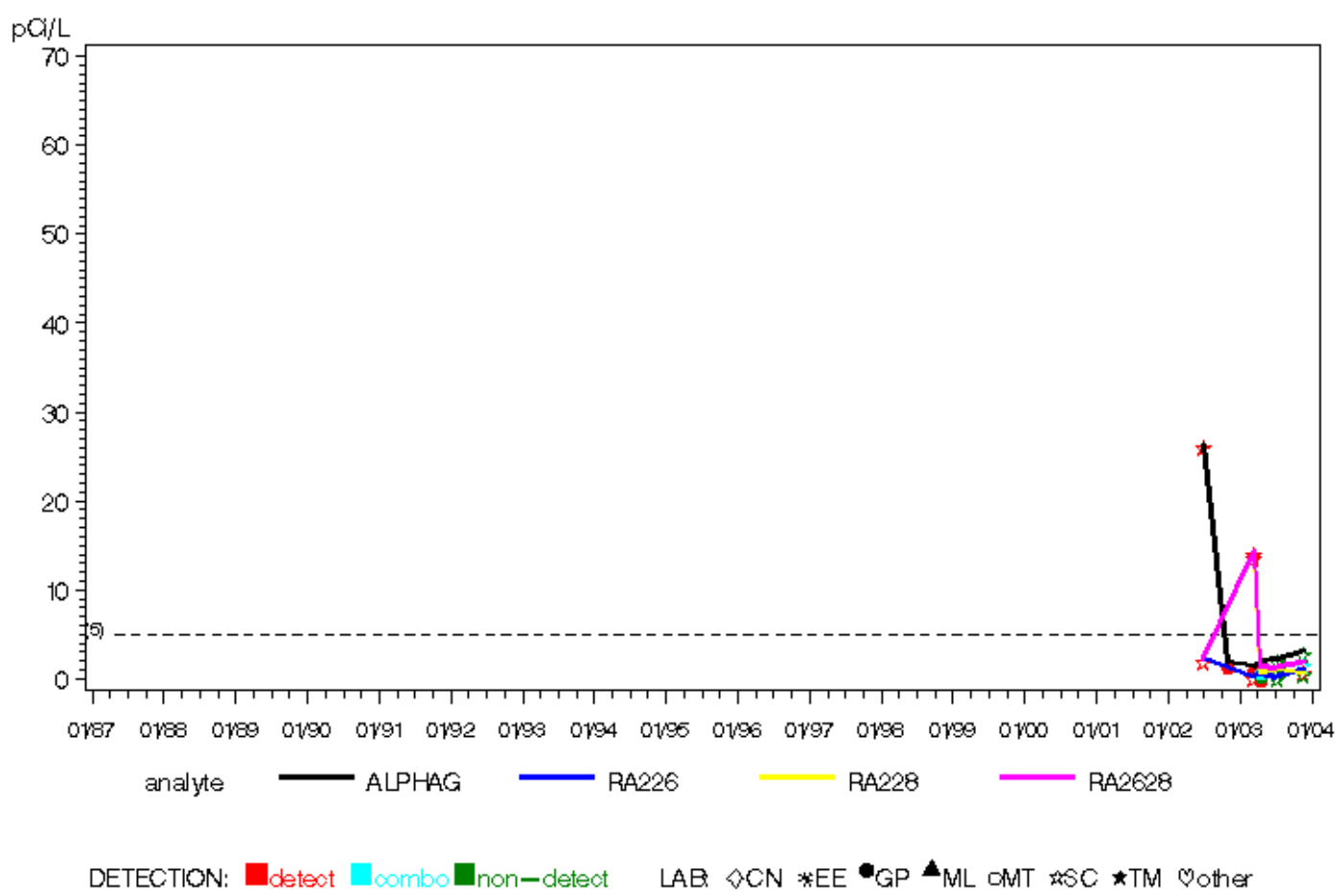


FINAL REPORT: Ra in the SLF WSRC-TR-2004-00141

SLF Wells (LFW, LFP Series): Recent Elevated Radium WELL $=$ LFP 1 औNP

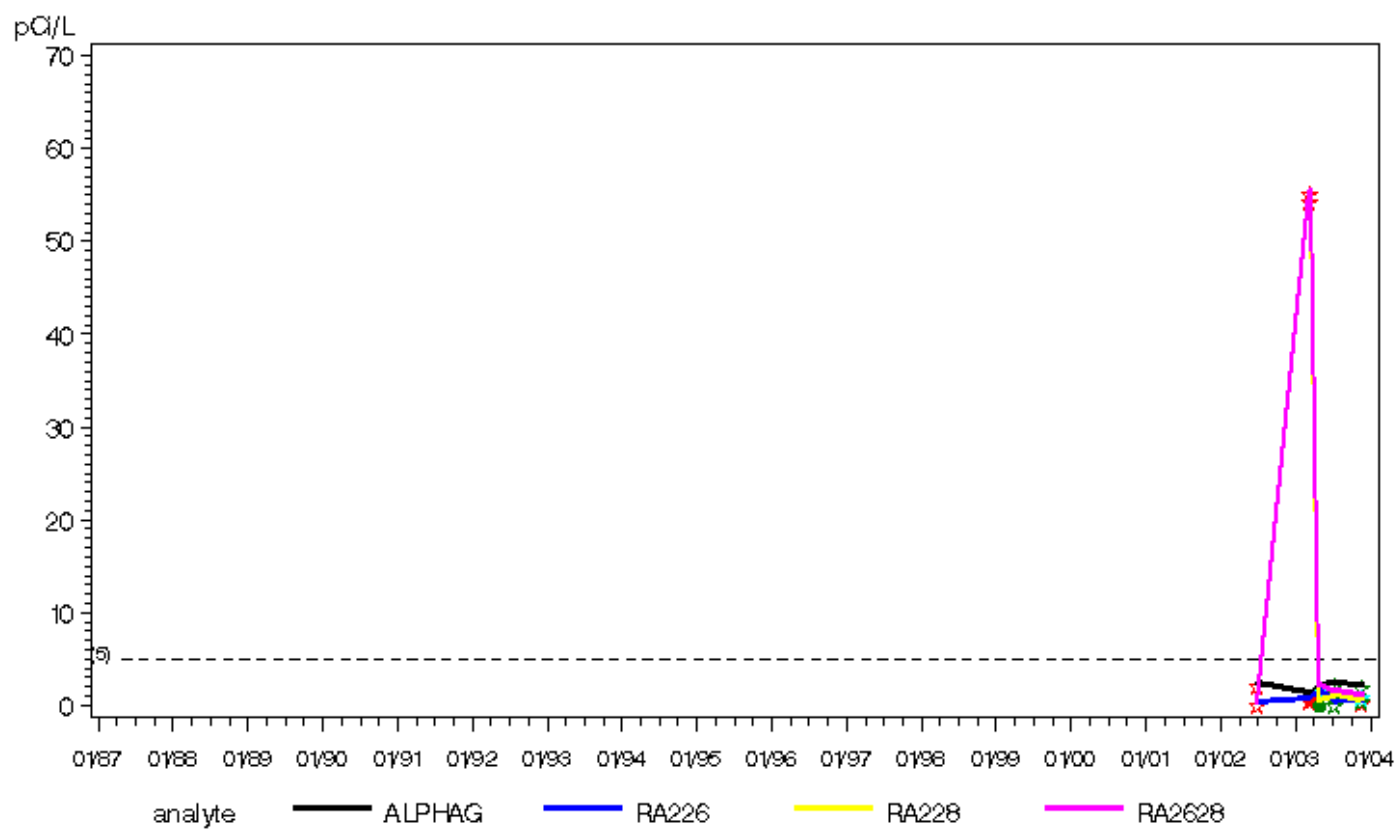

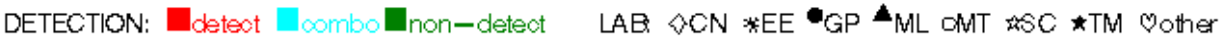

SLF Wells (LFW, LFP Series): Recent Elevated Radium WELL=LFW 8R

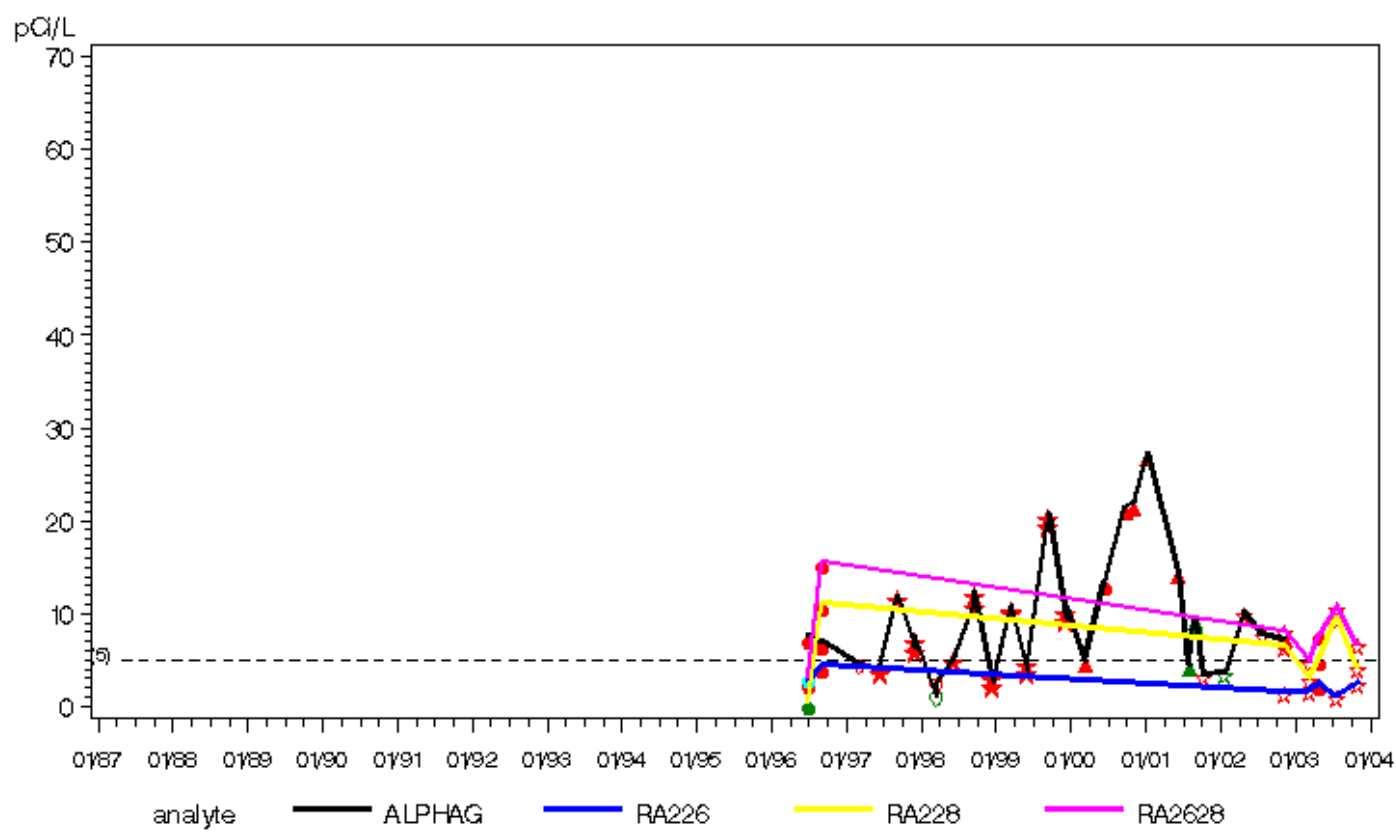

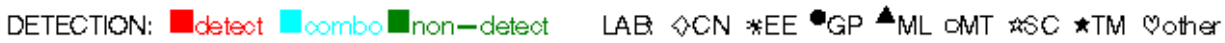


FINAL REPORT: Ra in the SLF WSRC-TR-2004-00141

\section{SLF Wells (LFW, LFP Series): Recent Elevated Radium WELL $=$ LFW 18}

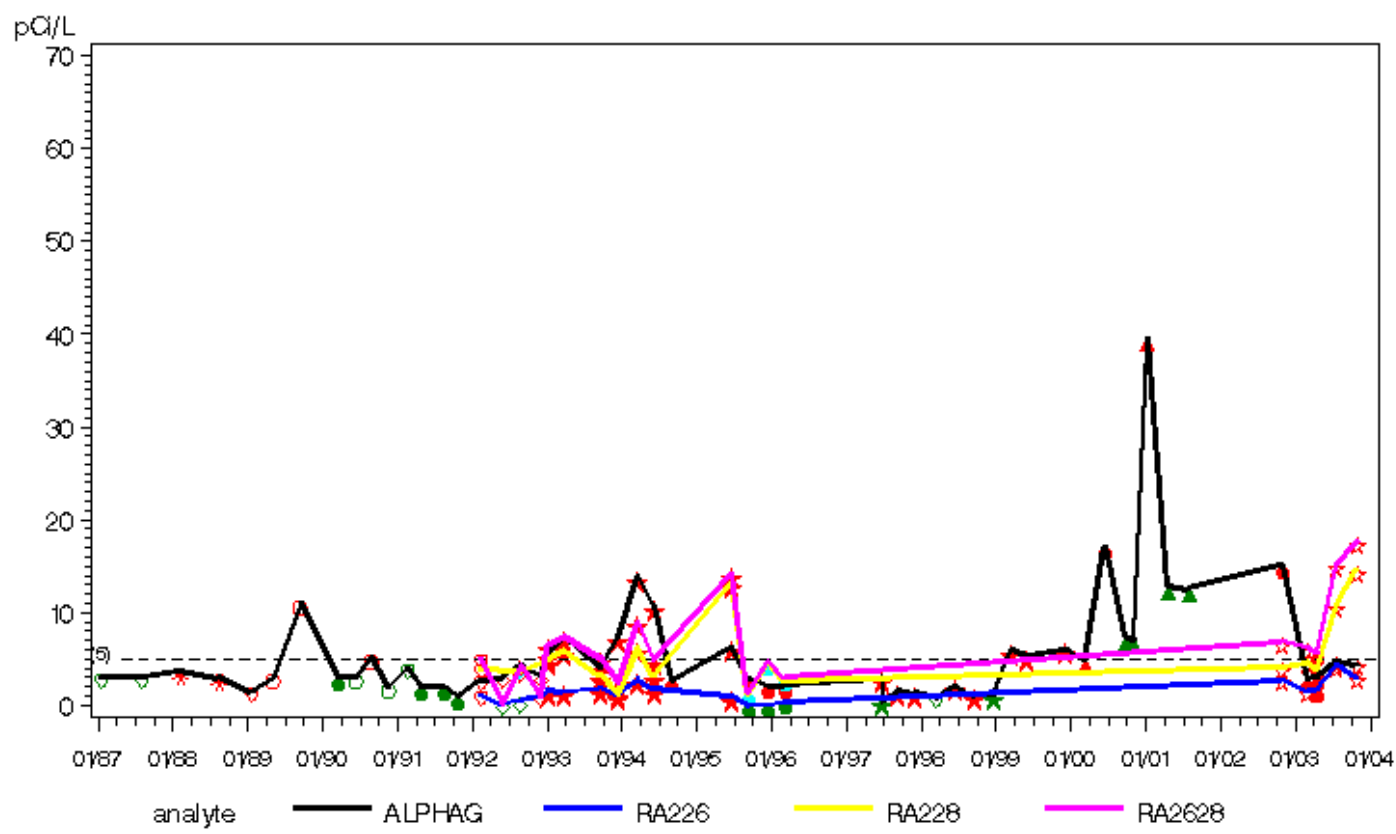

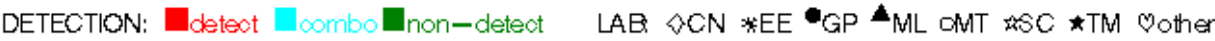

SLF Wells (LFW, LFP Series): Recent Elevated Radium WELL=LFW 23R

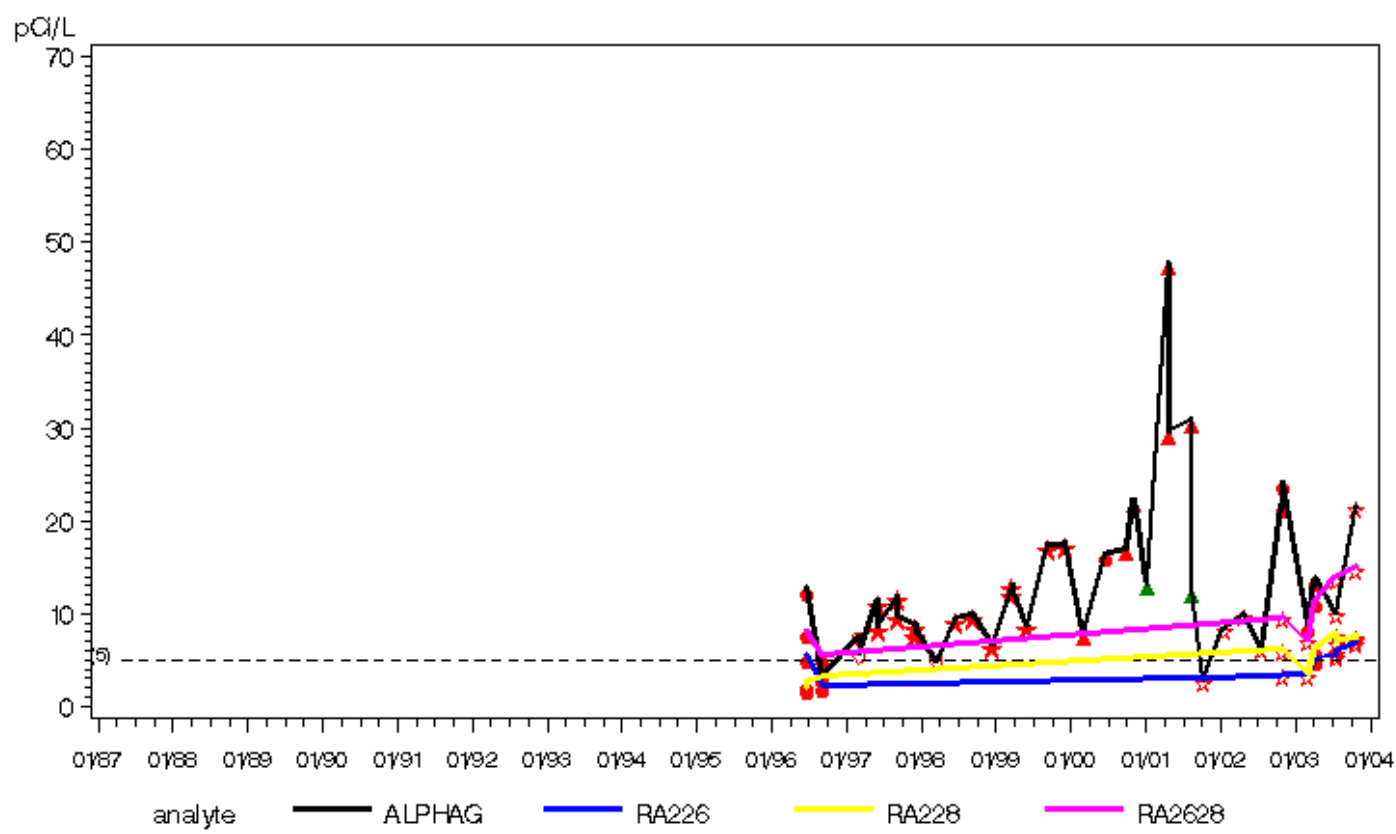

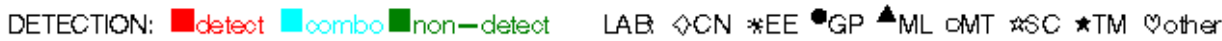


FINAL REPORT: Ra in the SLF WSRC-TR-2004-00141

\section{SLF Wells (LFW, LFP Series): Recent Elevated Radium \\ WELL= LFW 29}

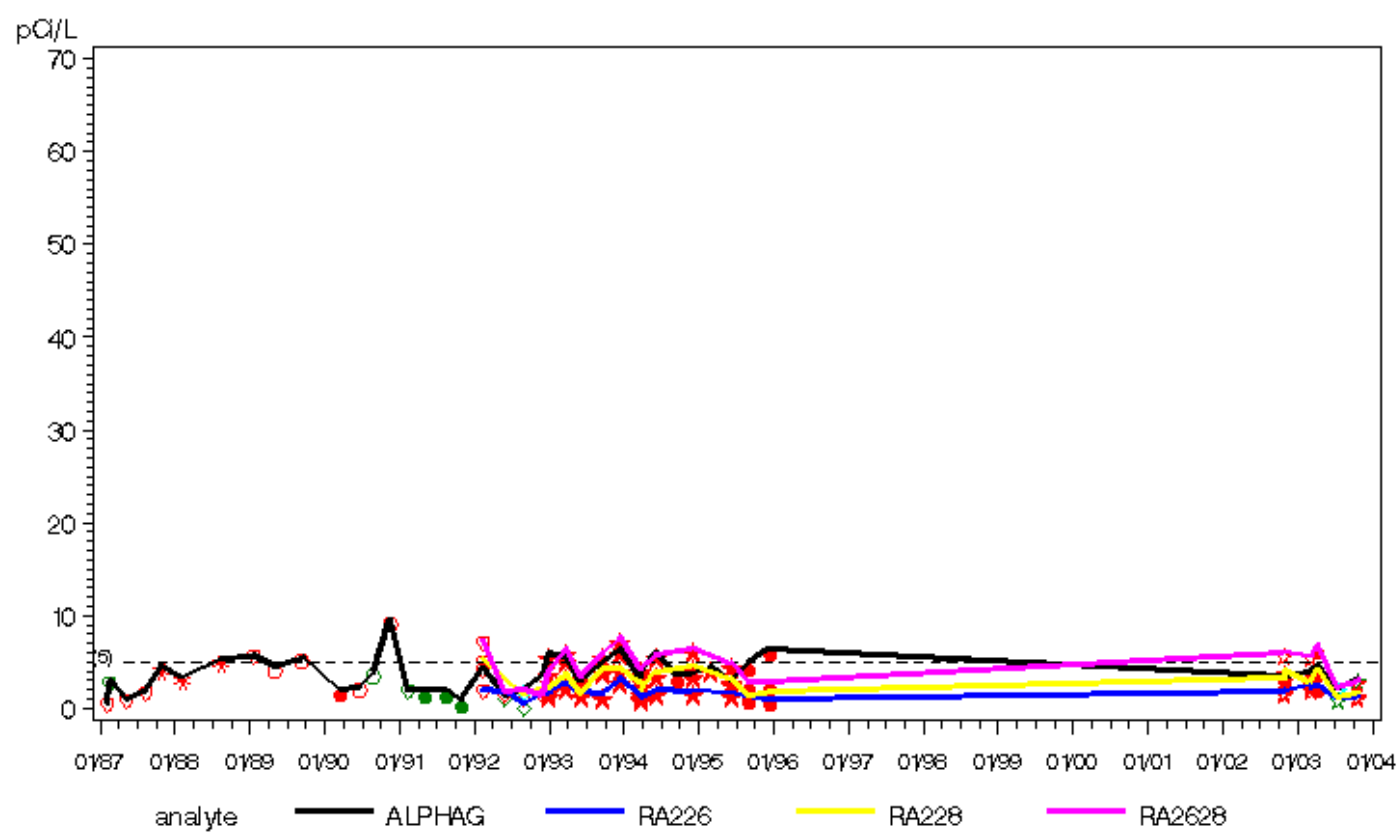

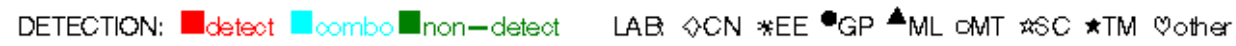

SLF Wells (LFW, LFP Series): Recent Elevated Radium WELL $=$ LFW $36 \mathrm{R}$

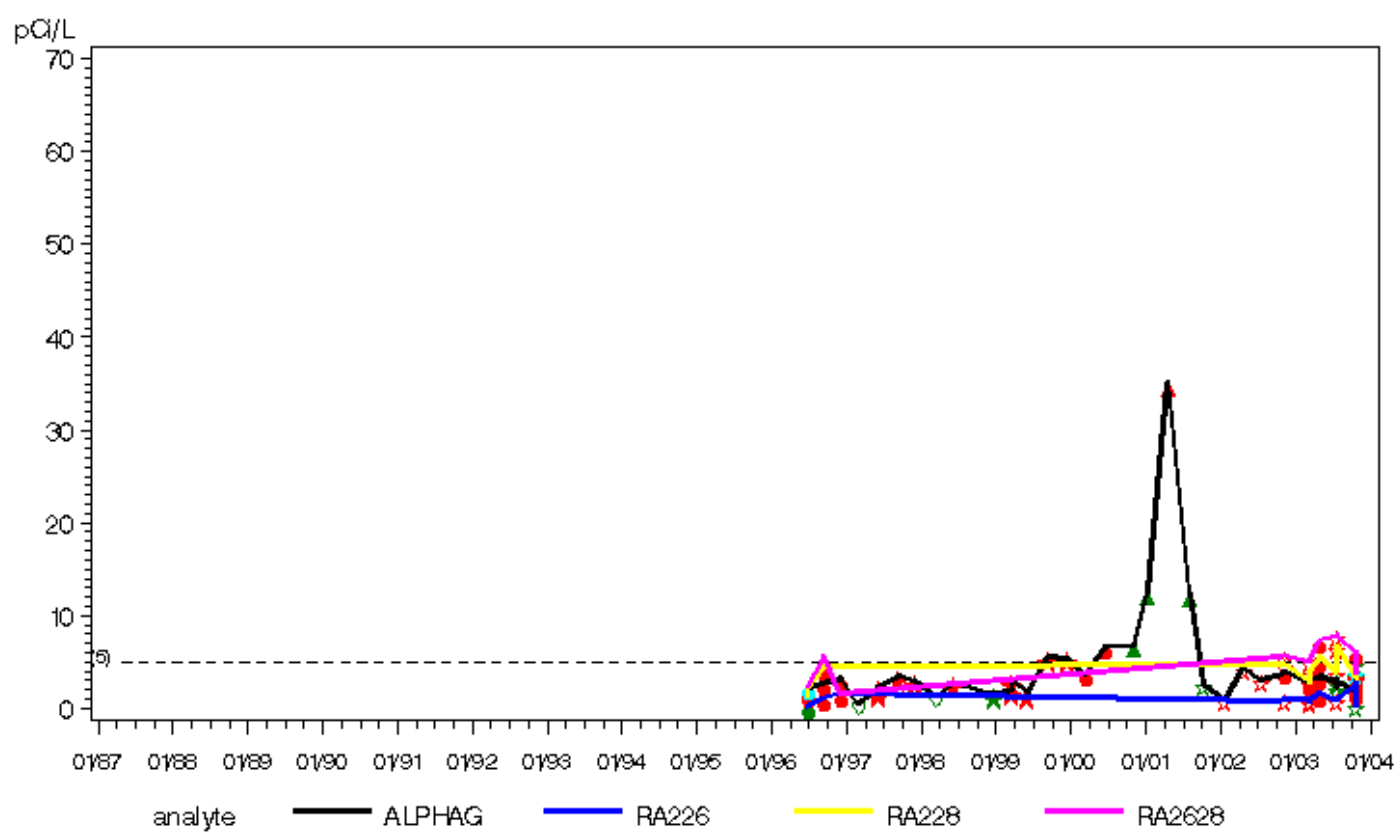

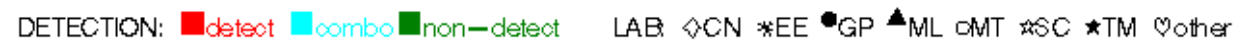


FINAL REPORT: Ra in the SLF WSRC-TR-2004-00141

SLF Wells (LFW, LFP Series): Recent Elevated Radium WELL=LFW 41R

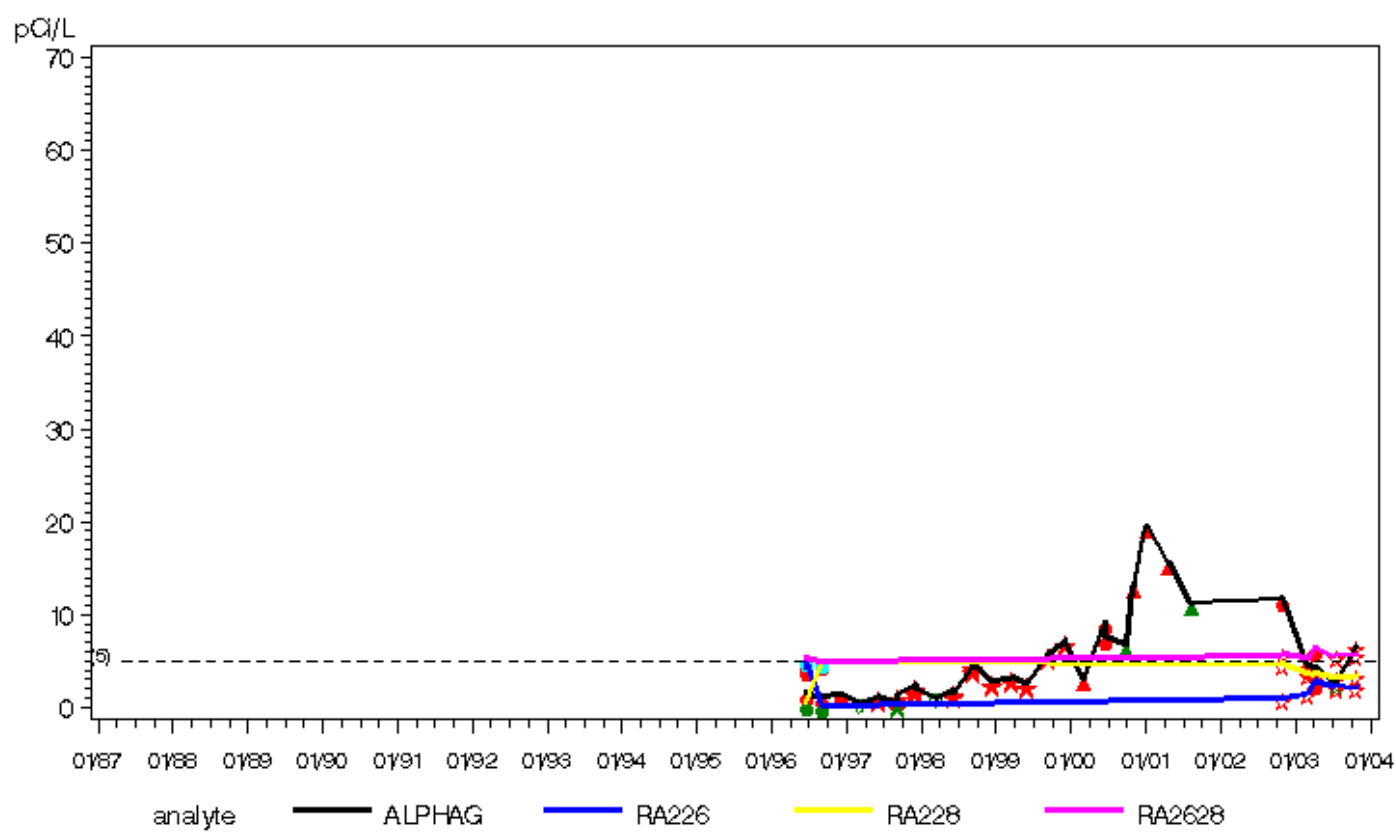

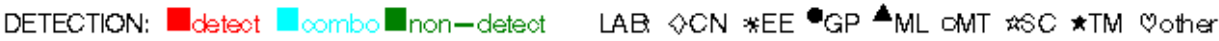

SLF Wells (LFW, LFP Series): Recent Elevated Radium WELL= LFW 45D

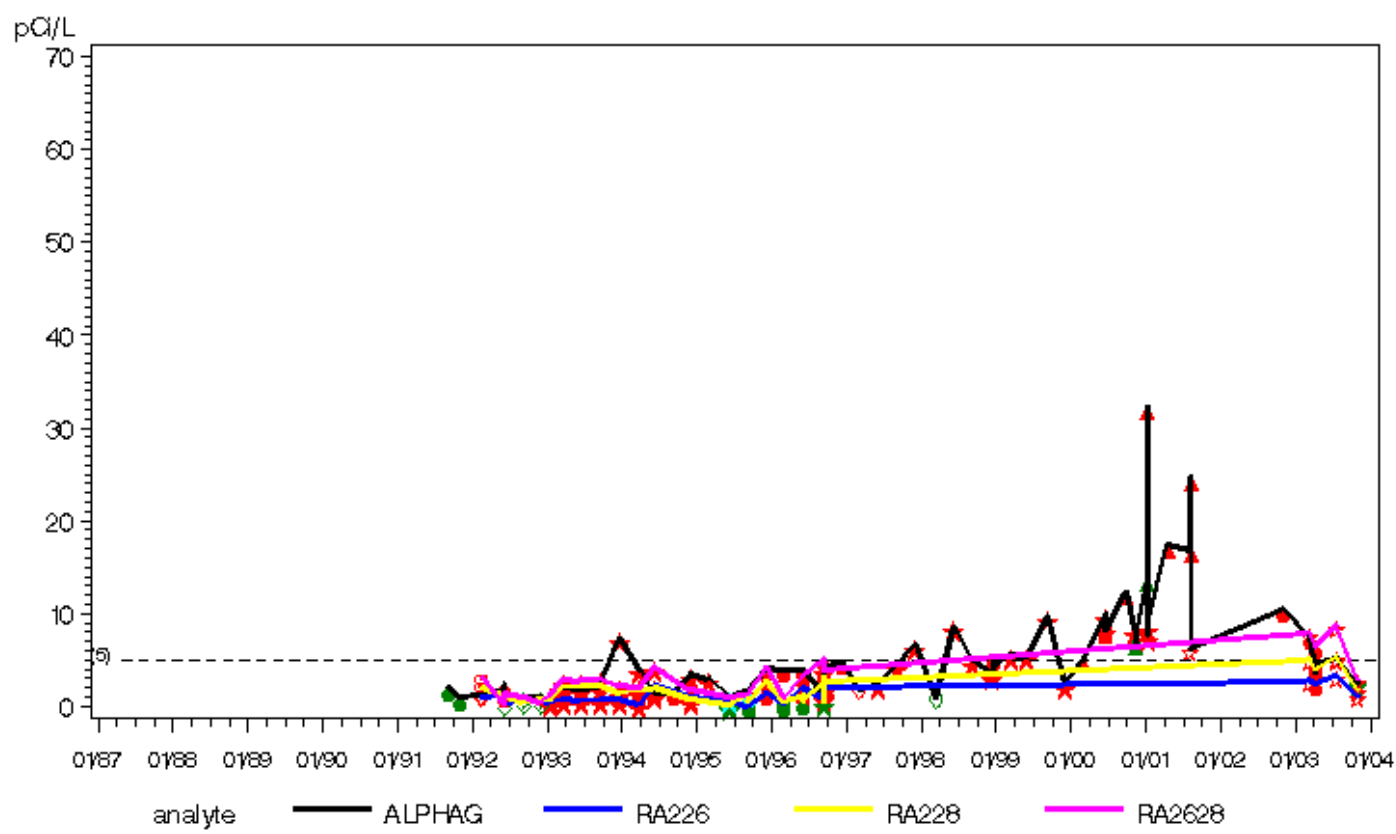

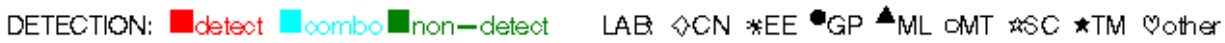


FINAL REPORT: Ra in the SLF WSRC-TR-2004-00141

\section{SLF Wells (LFW, LFP Series): Recent Elevated Radium WELL $=$ LFW $47 \mathrm{C}$}

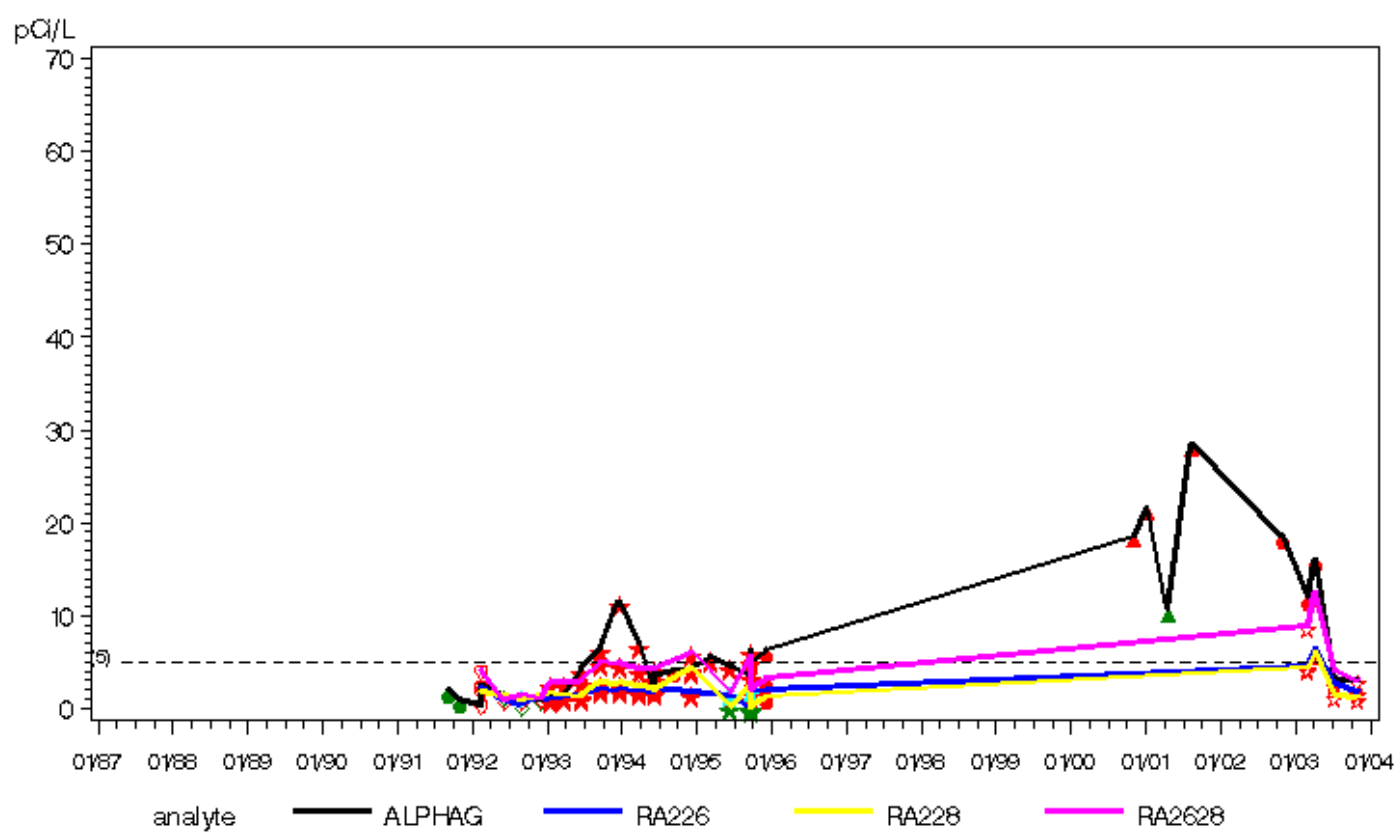

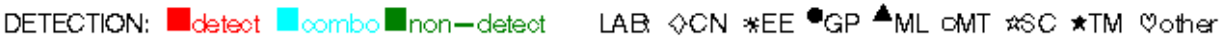

SLF Wells (LFW, LFP Series): Recent Elevated Radium WELL $=$ LFW $57 \mathrm{~B}$

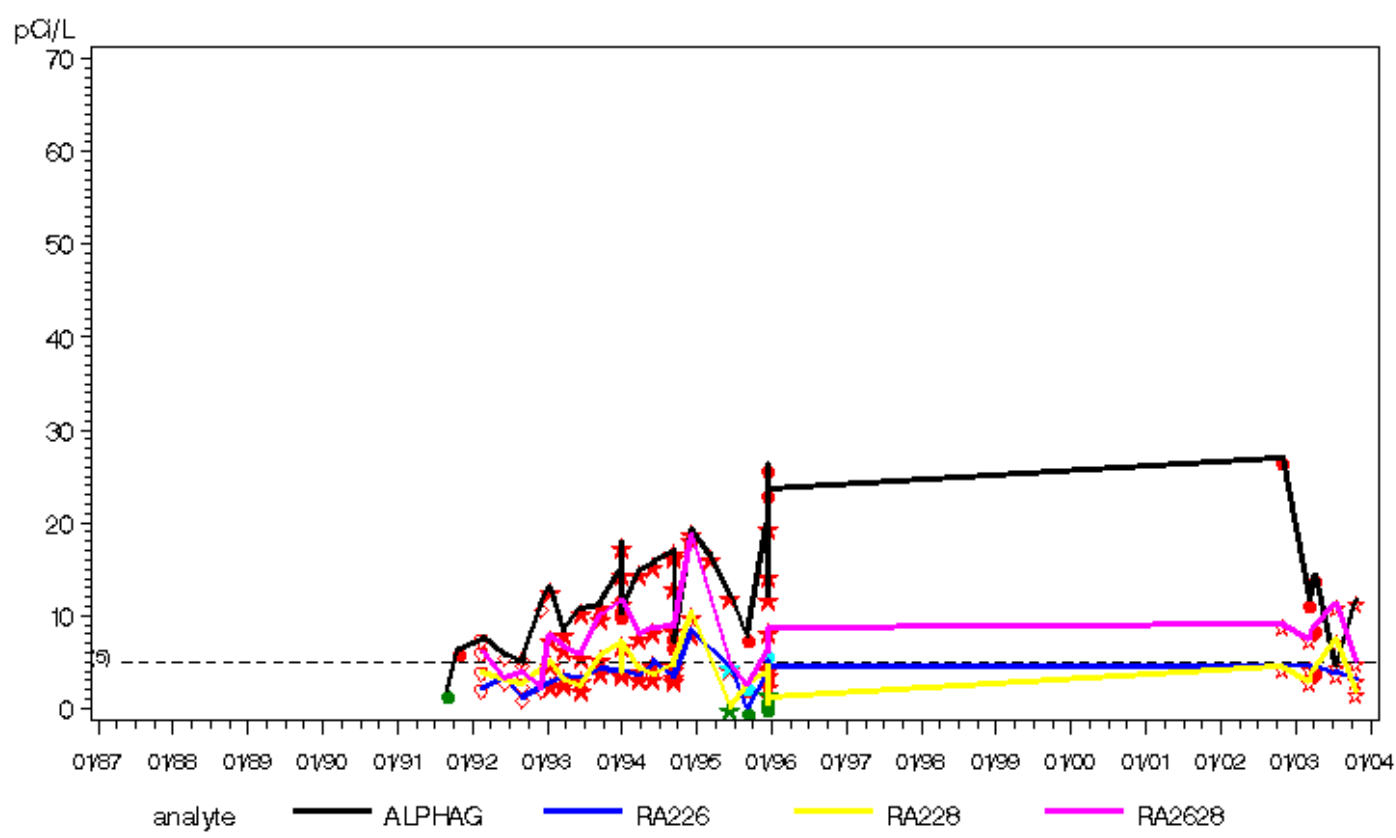

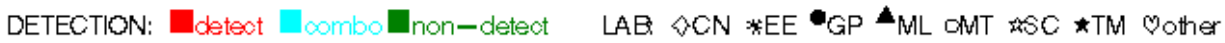


FINAL REPORT: $\mathrm{Ra}$ in the SLF WSRC-TR-2004-00141

SLF Wells (LFW, LFP Series): Recent Elevated Radium WELL $=L F W 62 B$

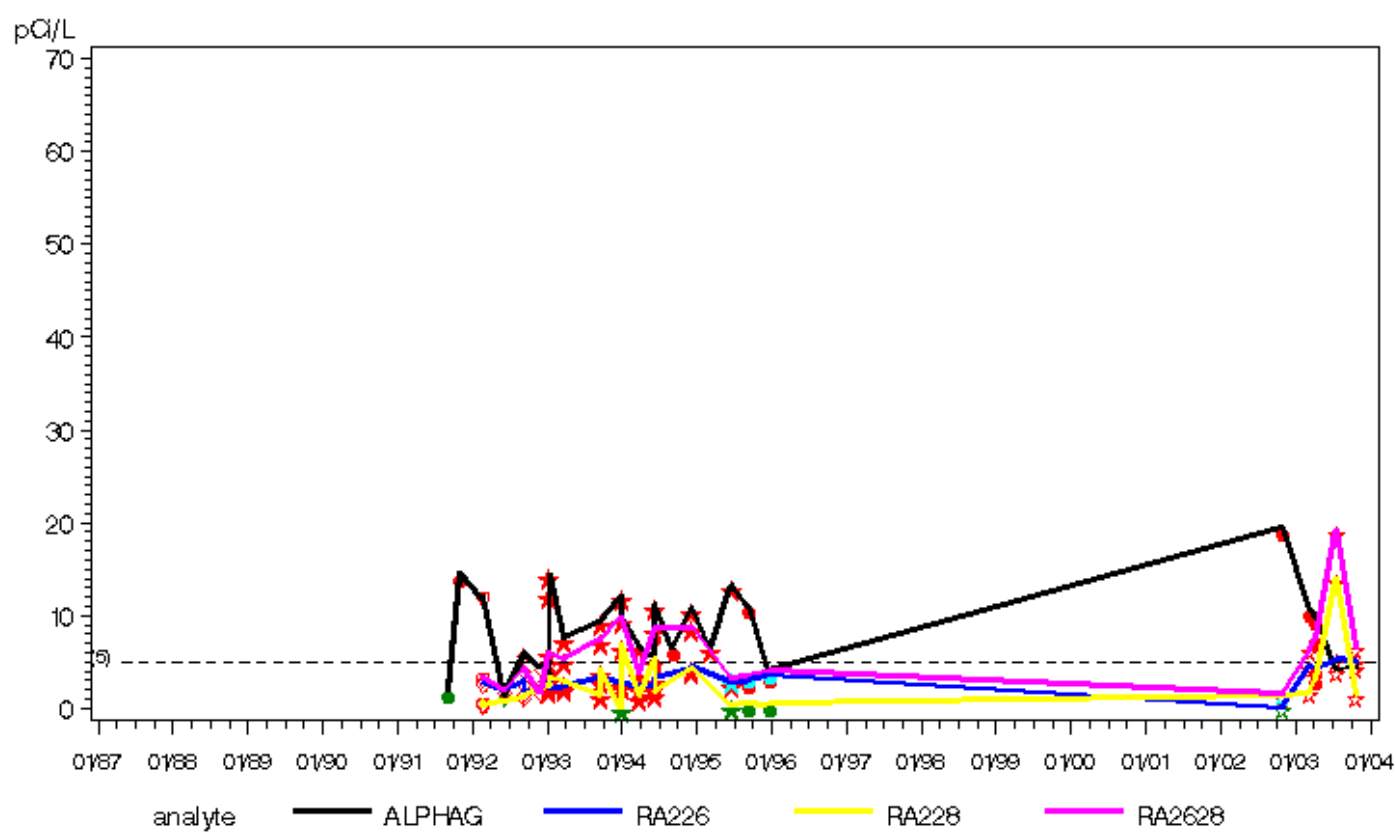

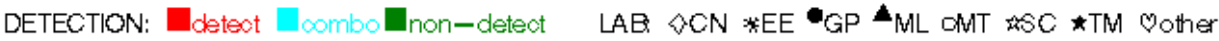

SLF Wells (LFW, LFP Series): Recent Elevated Radium WELL= LFW $64 \mathrm{C}$

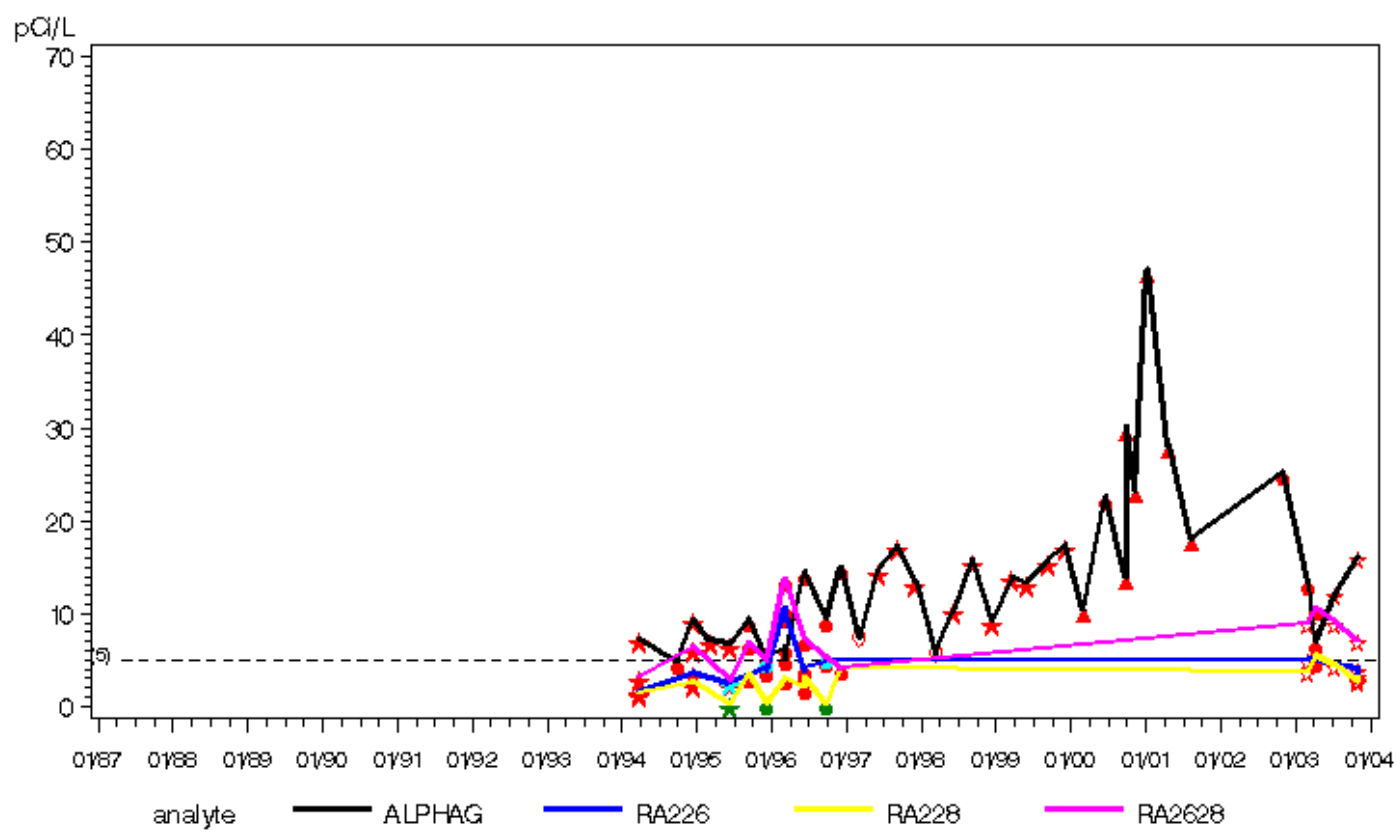

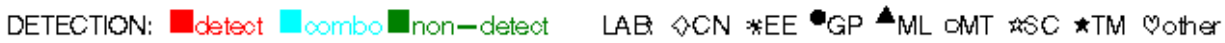


FINAL REPORT: Ra in the SLF WSRC-TR-2004-00141

\section{SLF Wells (LFW, LFP Series): Recent Elevated Radium WELL $=$ LFW $Q 6 \mathrm{~B}$}

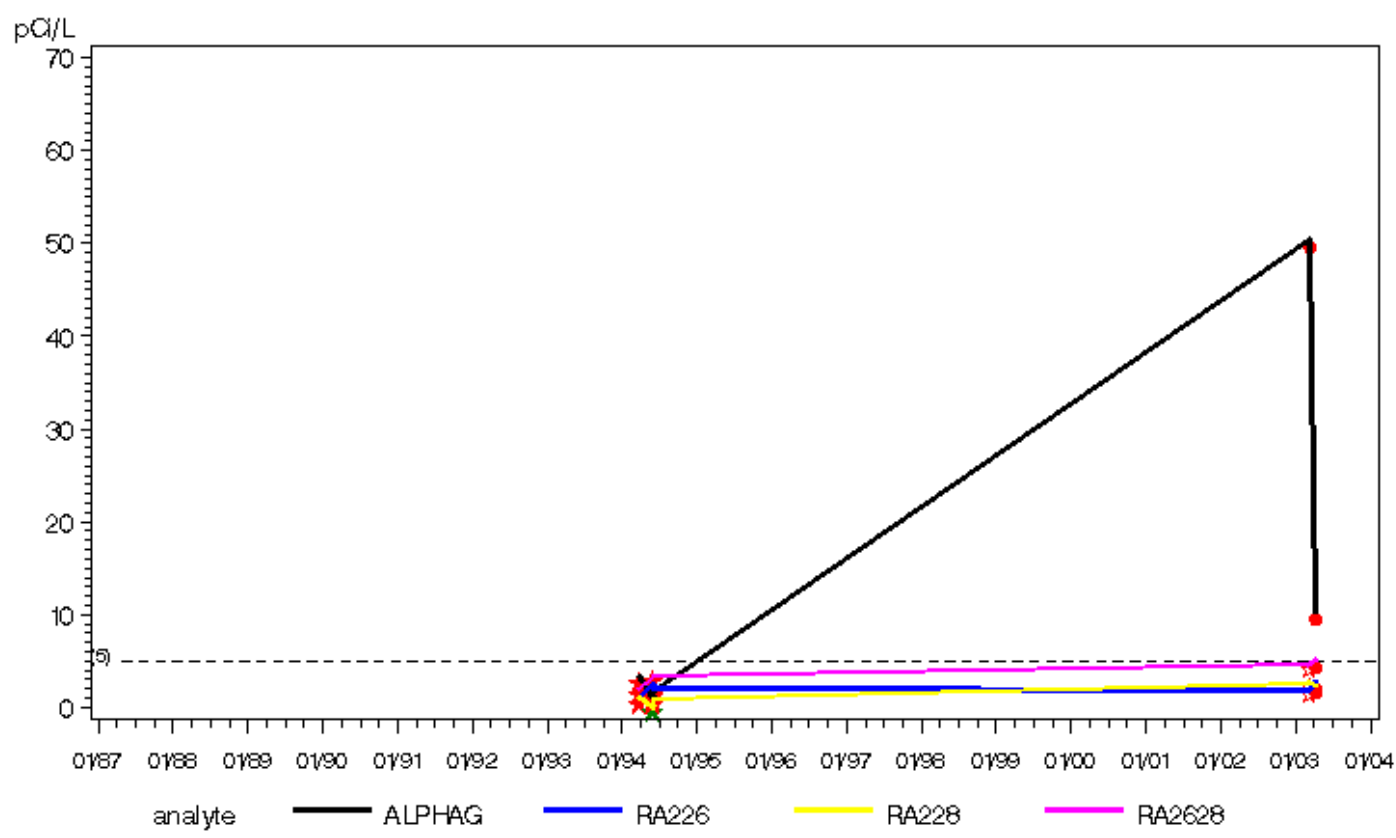

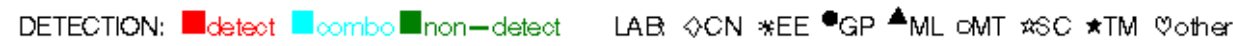

SLF Wells (LFW, LFP Series): Recent Elevated Radium WELL $=$ LFW $67 \mathrm{~B}$

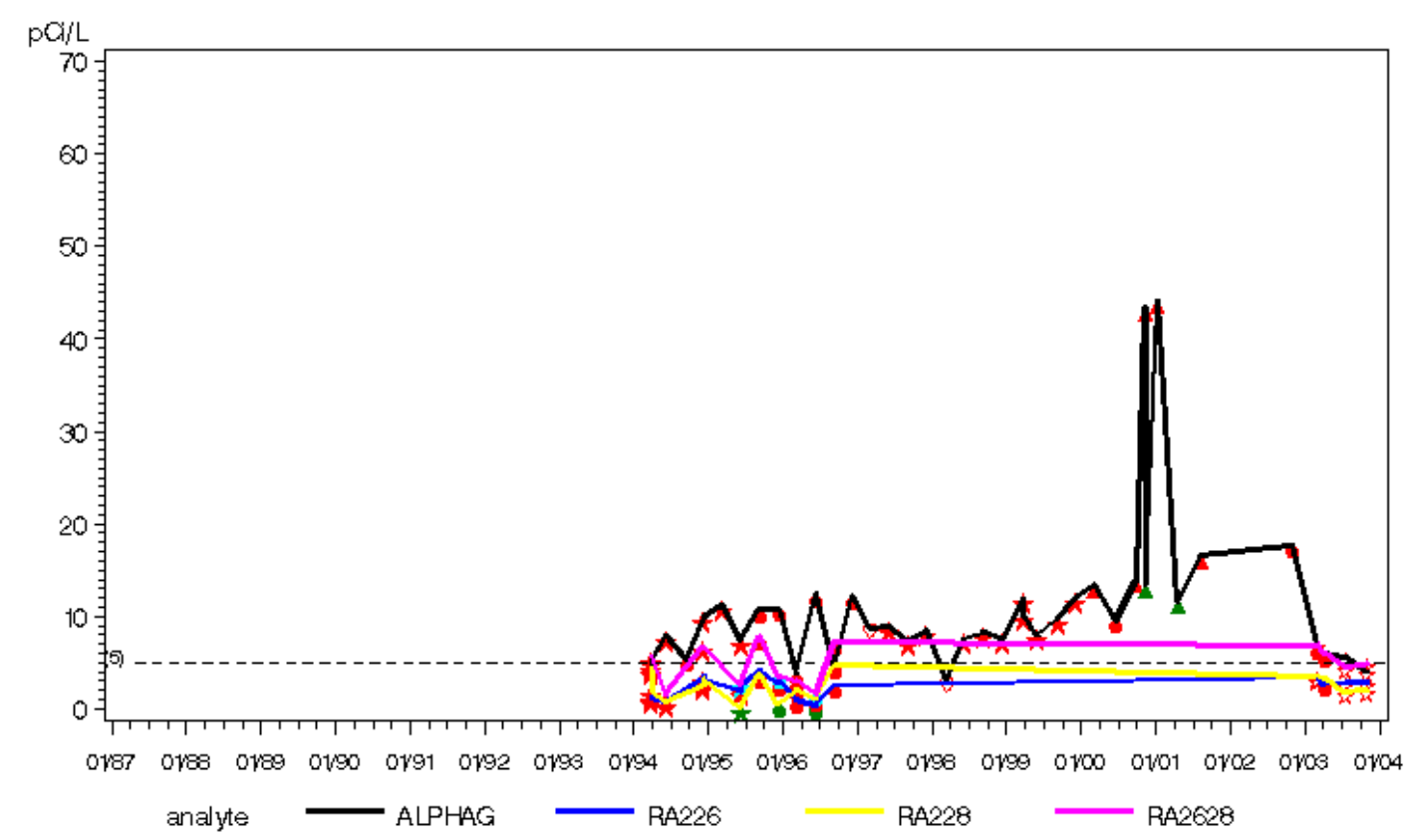

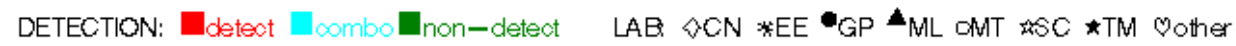


FINAL REPORT: Ra in the SLF WSRC-TR-2004-00141

SLF Wells (LFW, LFP Series): Recent Elevated Radium WELL $=$ LFN $9 \mathrm{C}$

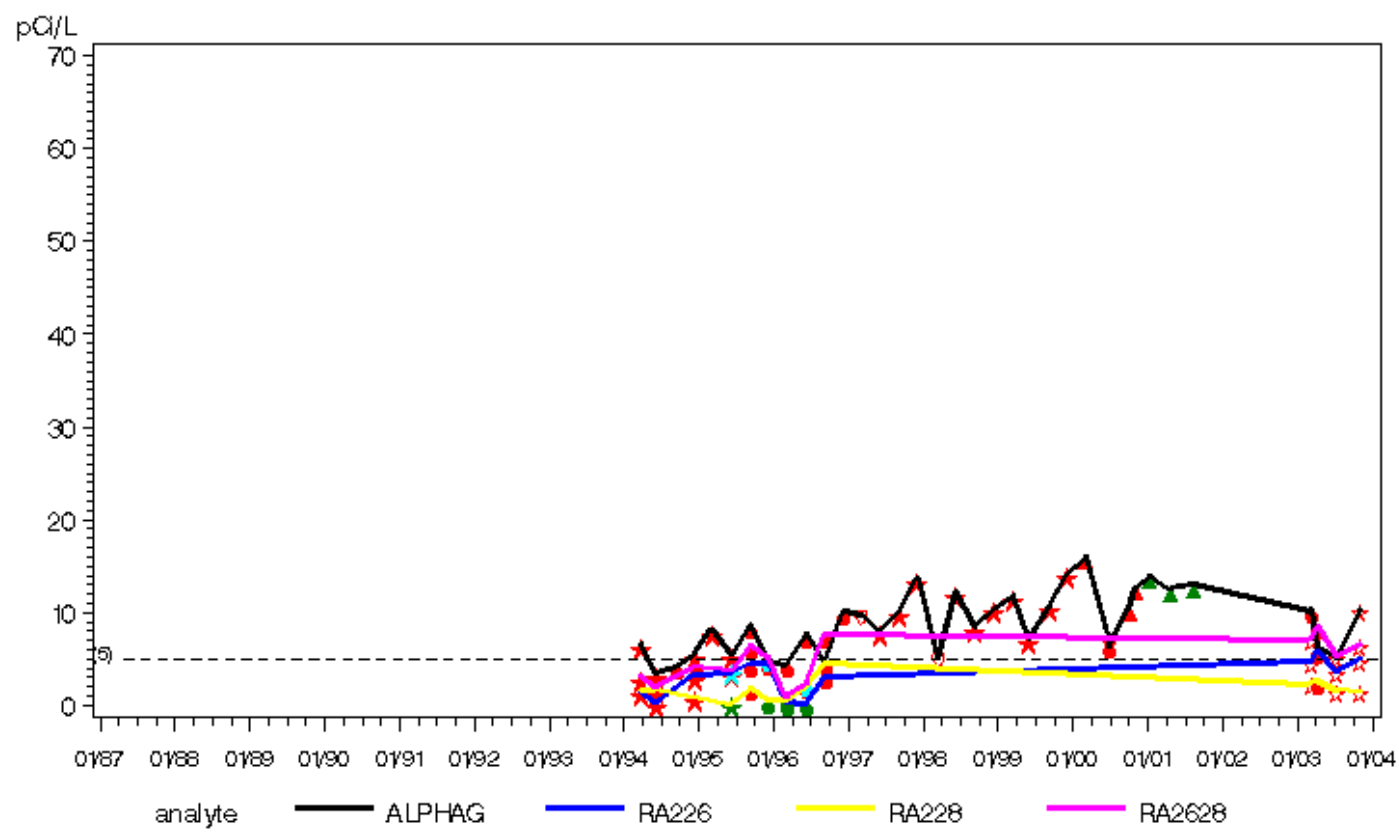

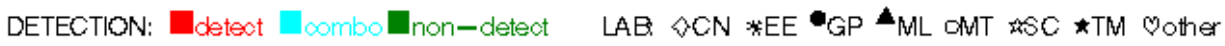


FINAL REPORT: Ra in the SLF WSRC-TR-2004-00141

\section{Appendix B2 - Time series plots by analyte}


FINAL REPORT: Ra in the SLF WSRC-TR-2004-00141

Ra226 in All LFP/LFW Wells

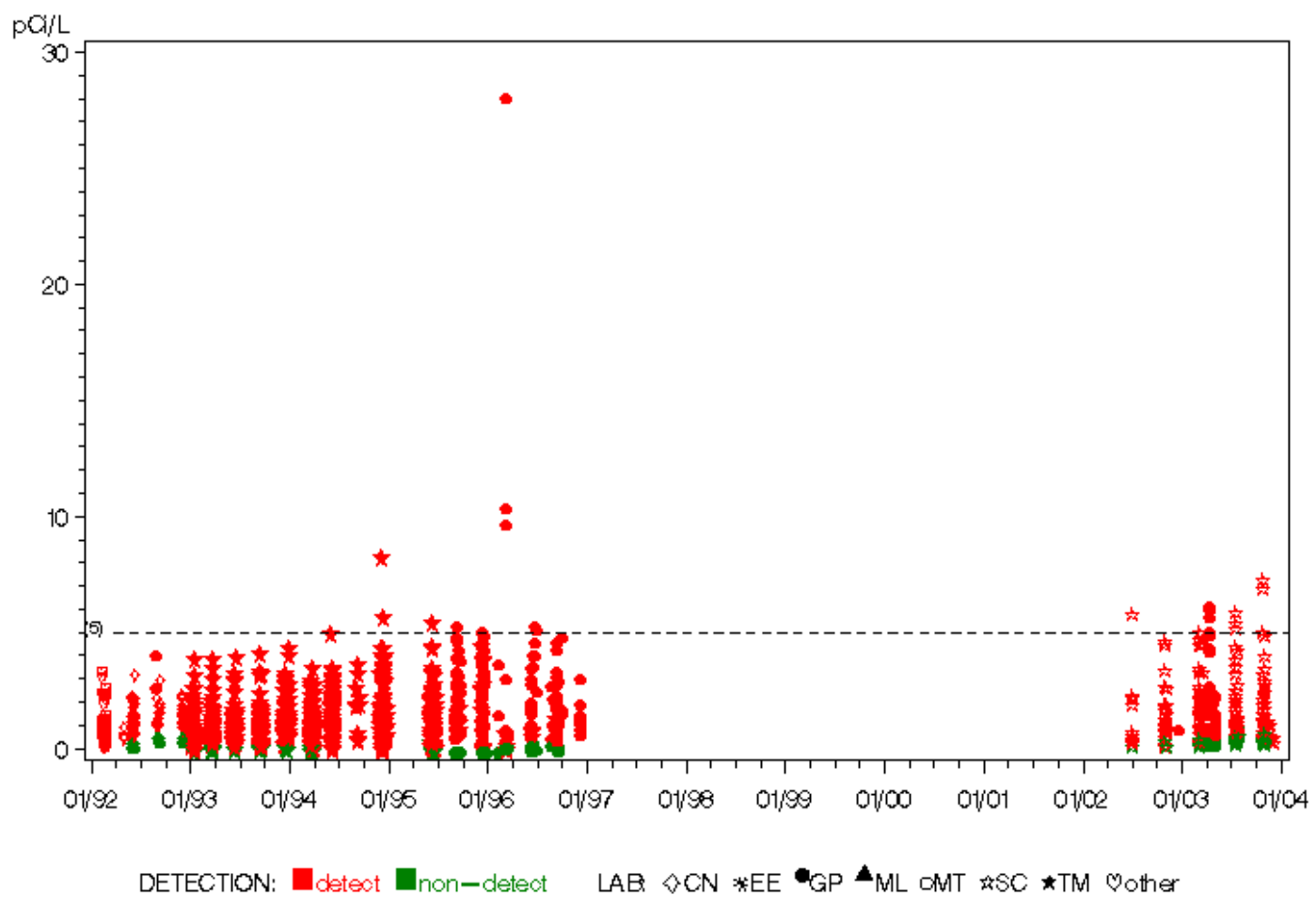

Ra228 in All LFP/LFW Wells

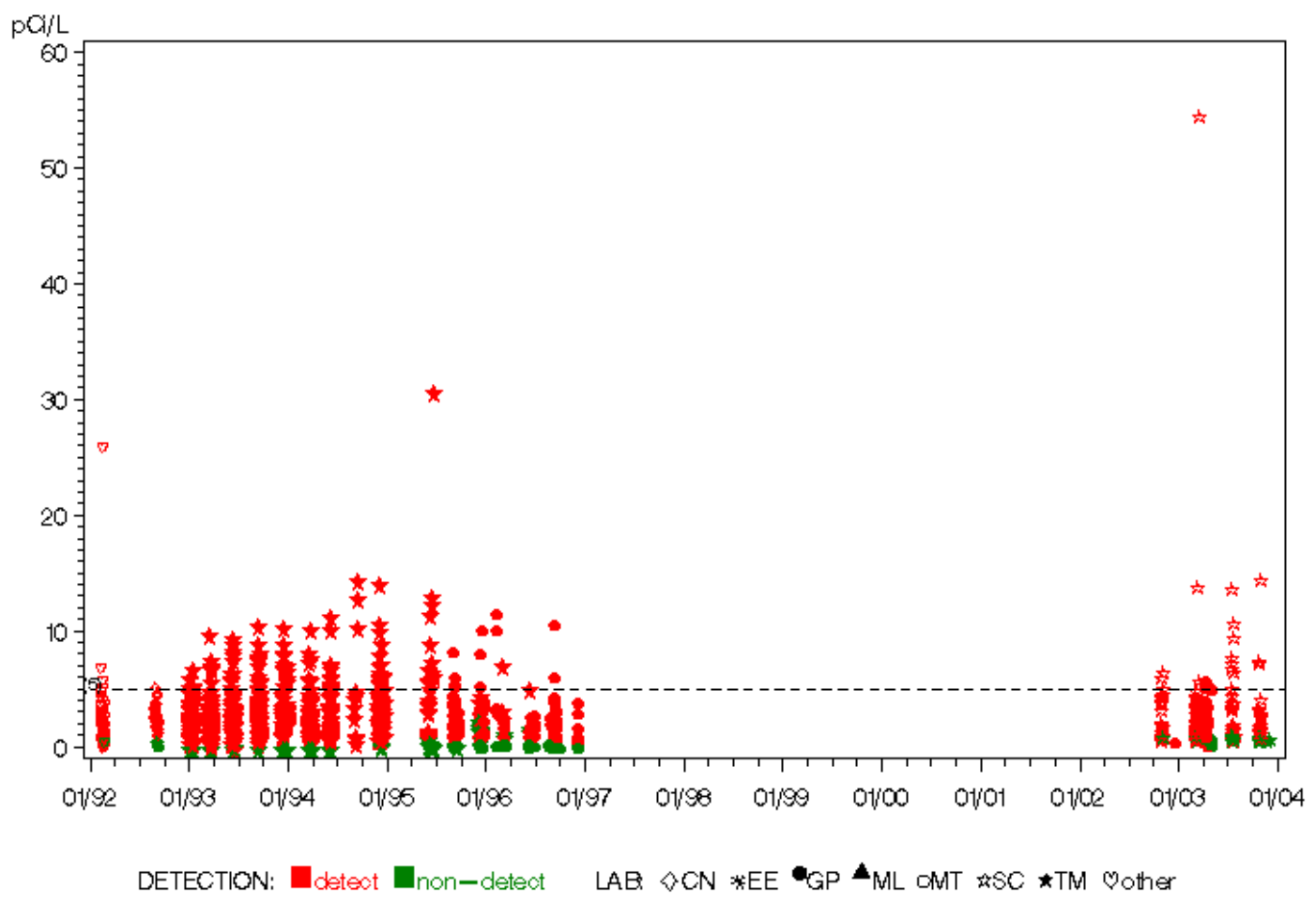


FINAL REPORT: Ra in the SLF WSRC-TR-2004-00141

\section{Ra226+Ra228 in All LFP/LFW Wells}

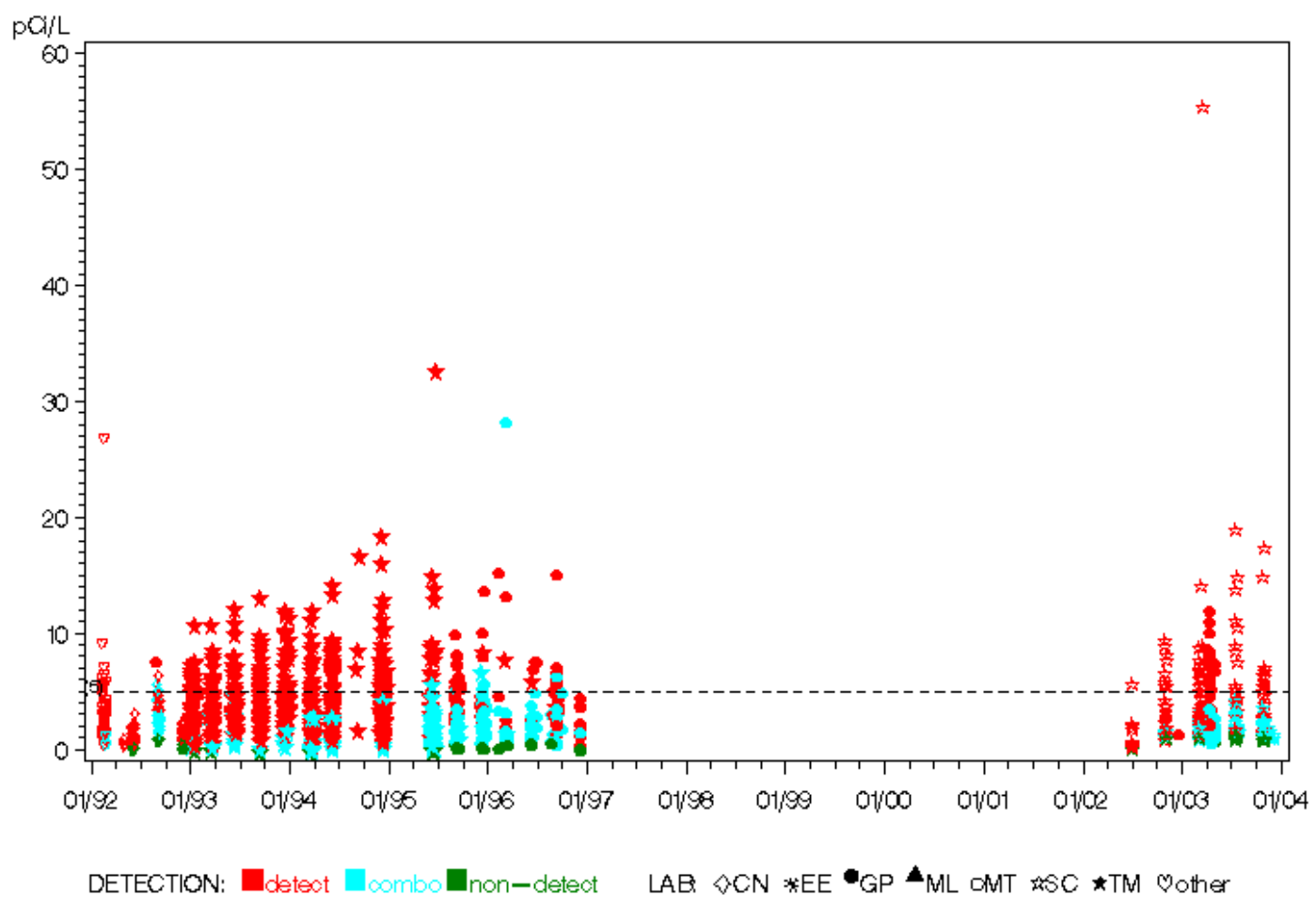

Gross Alpha in All LFP/LFW Wells

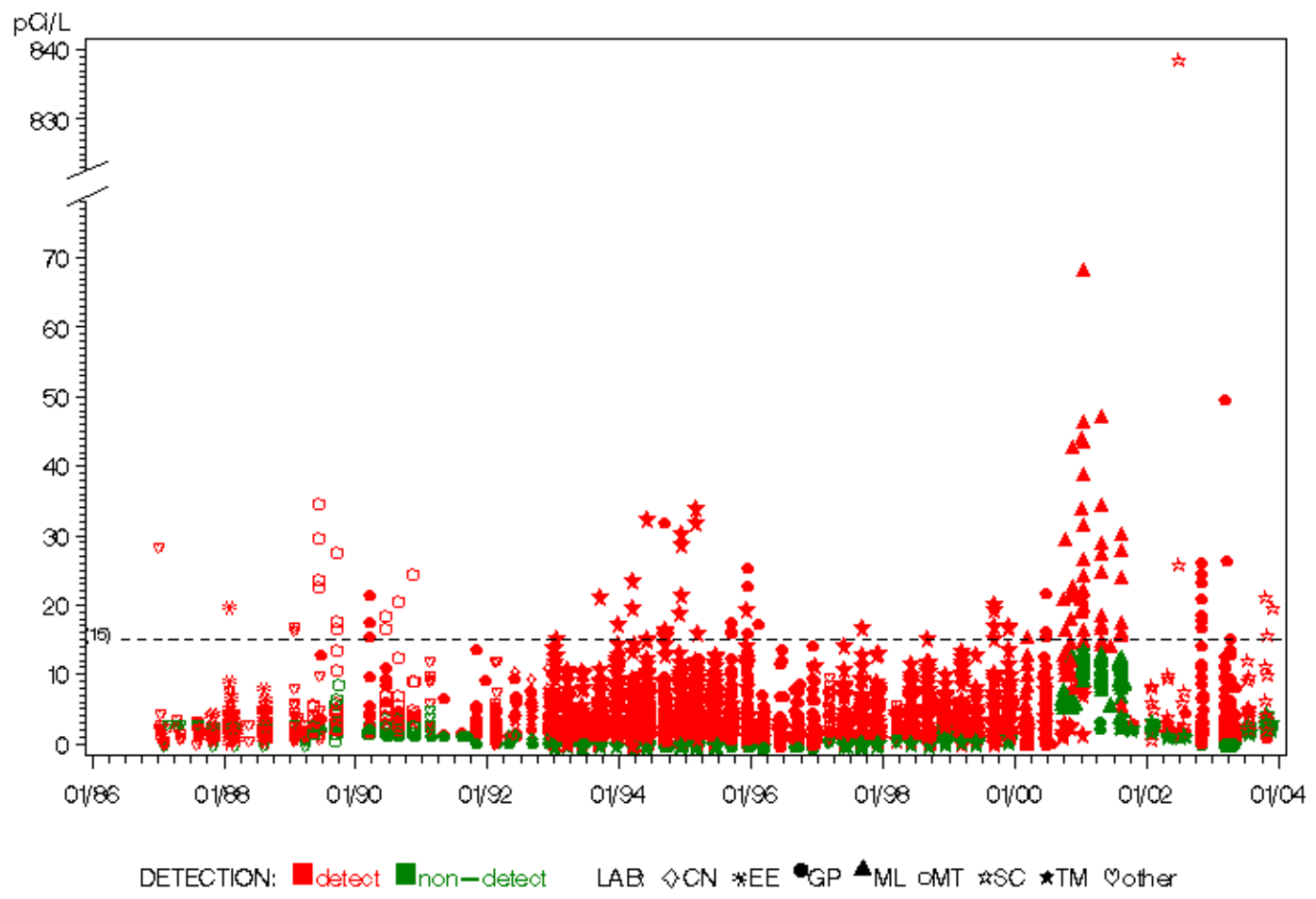


FINAL REPORT: Ra in the SLF WSRC-TR-2004-00141

Ratio of Detected Ra228 to Ra226 in All LFP/LFW Wells

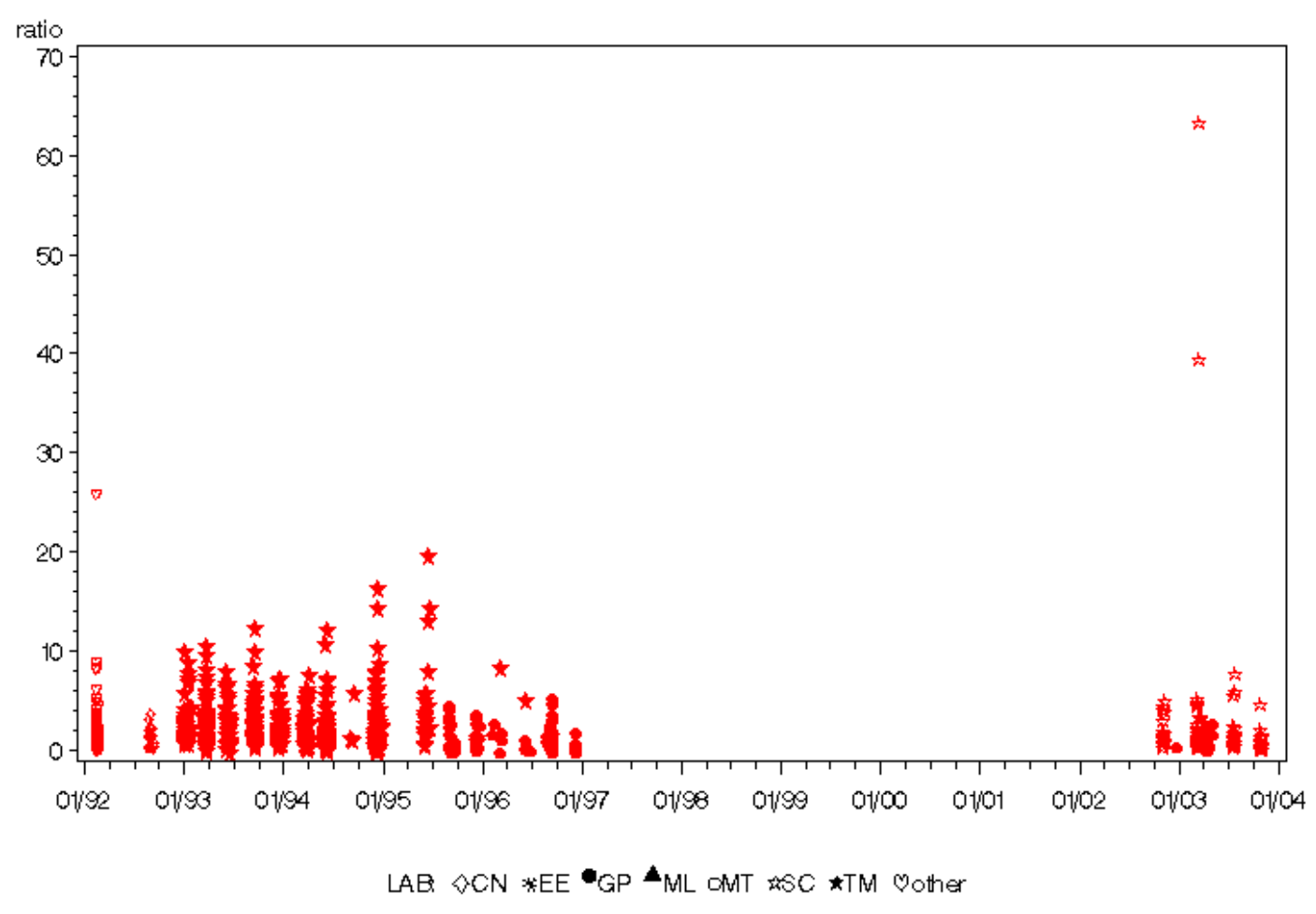




\section{Appendix B3 -Comparative Boxplots for Ra226, Ra228, and Gross Alpha}


FINAL REPORT: Ra in the SLF WSRC-TR-2004-00141

Log of Detected Ra226 in All LFP/LFW Wells and in Comparison Data

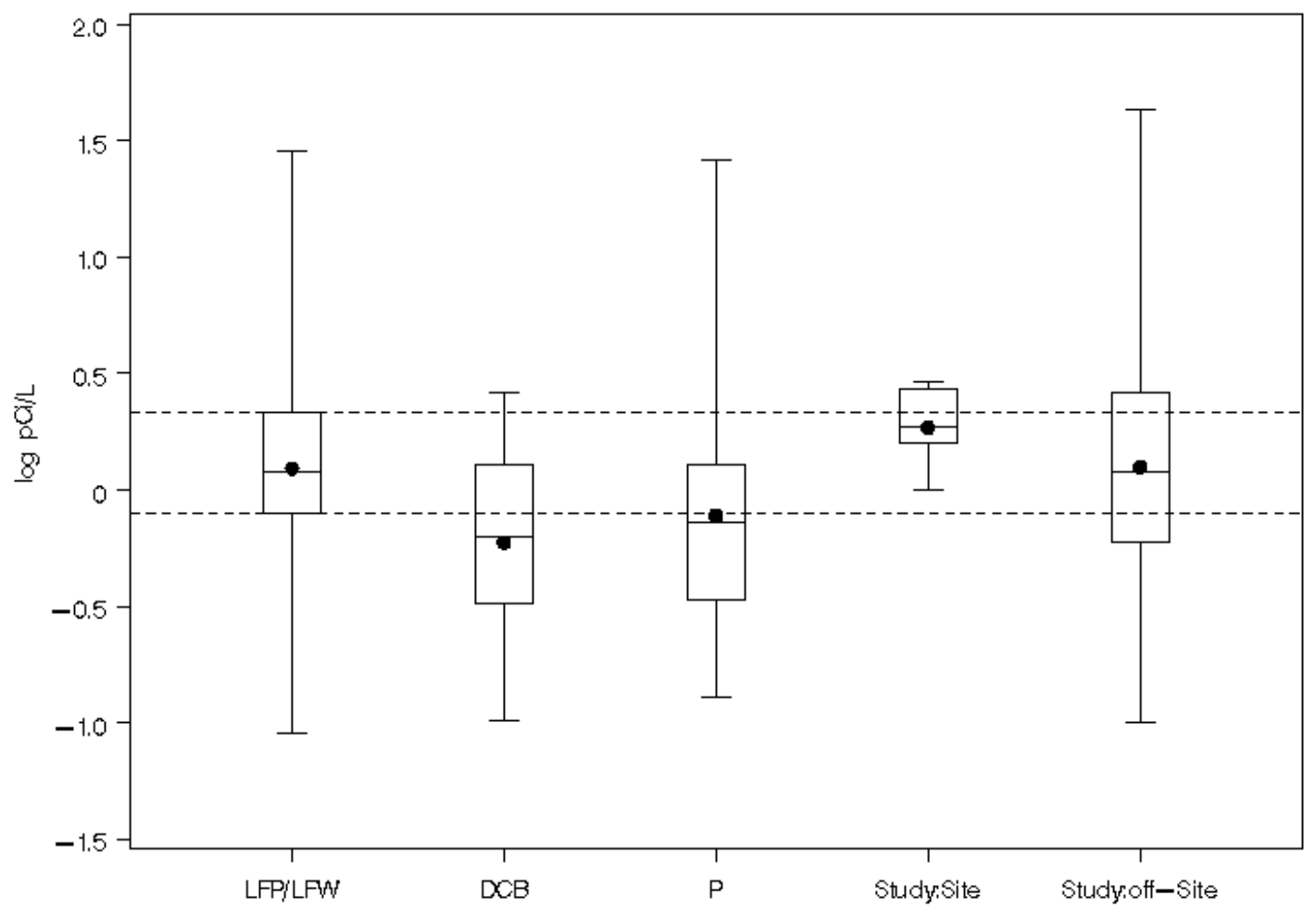

Log of Detected Ra228 in All LFP/LFW Wells and in Comparison Data

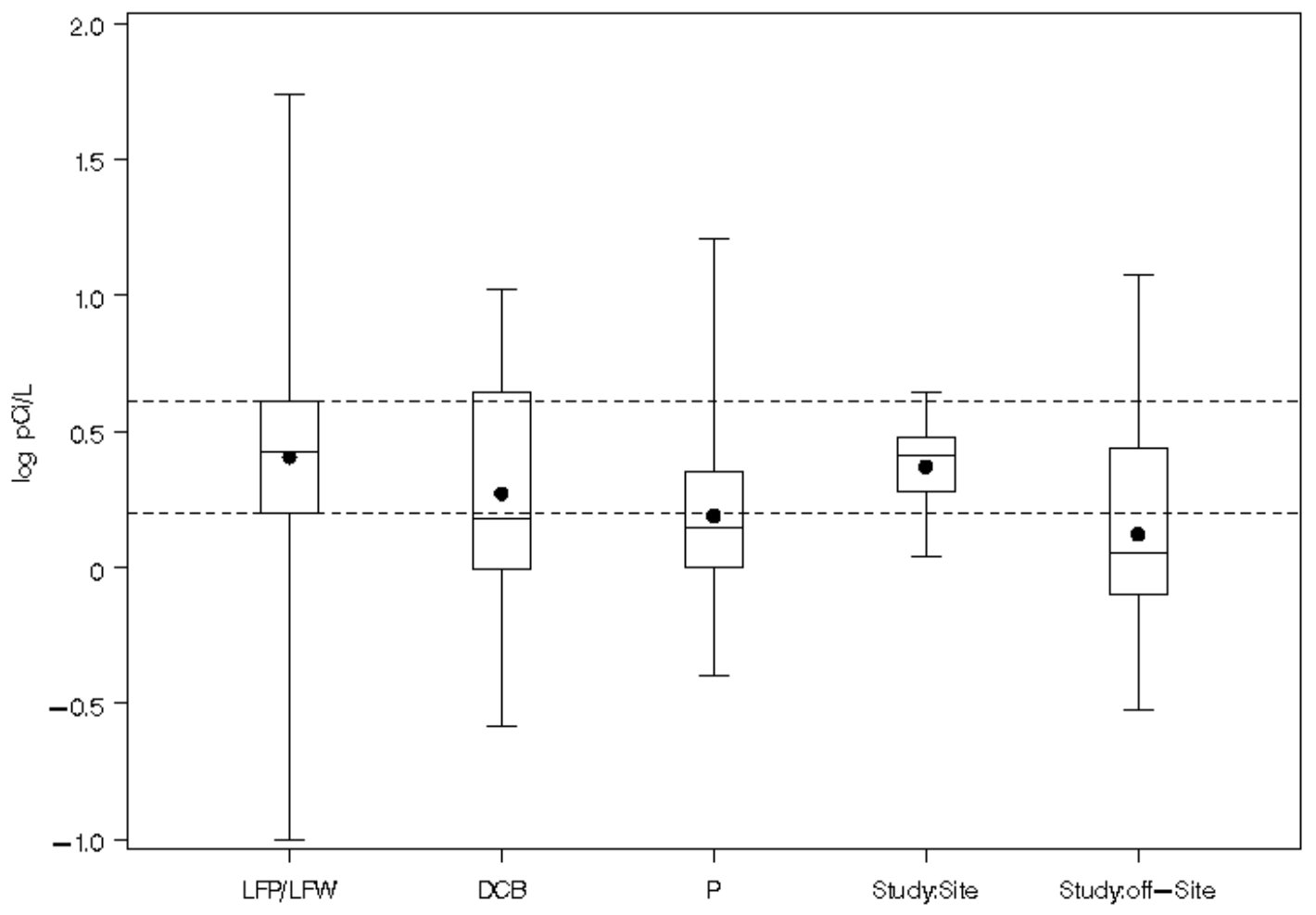


FINAL REPORT: Ra in the SLF WSRC-TR-2004-00141

Log of Detected Gross Alpha in All LFP/LFW Wells and in Comparison Data

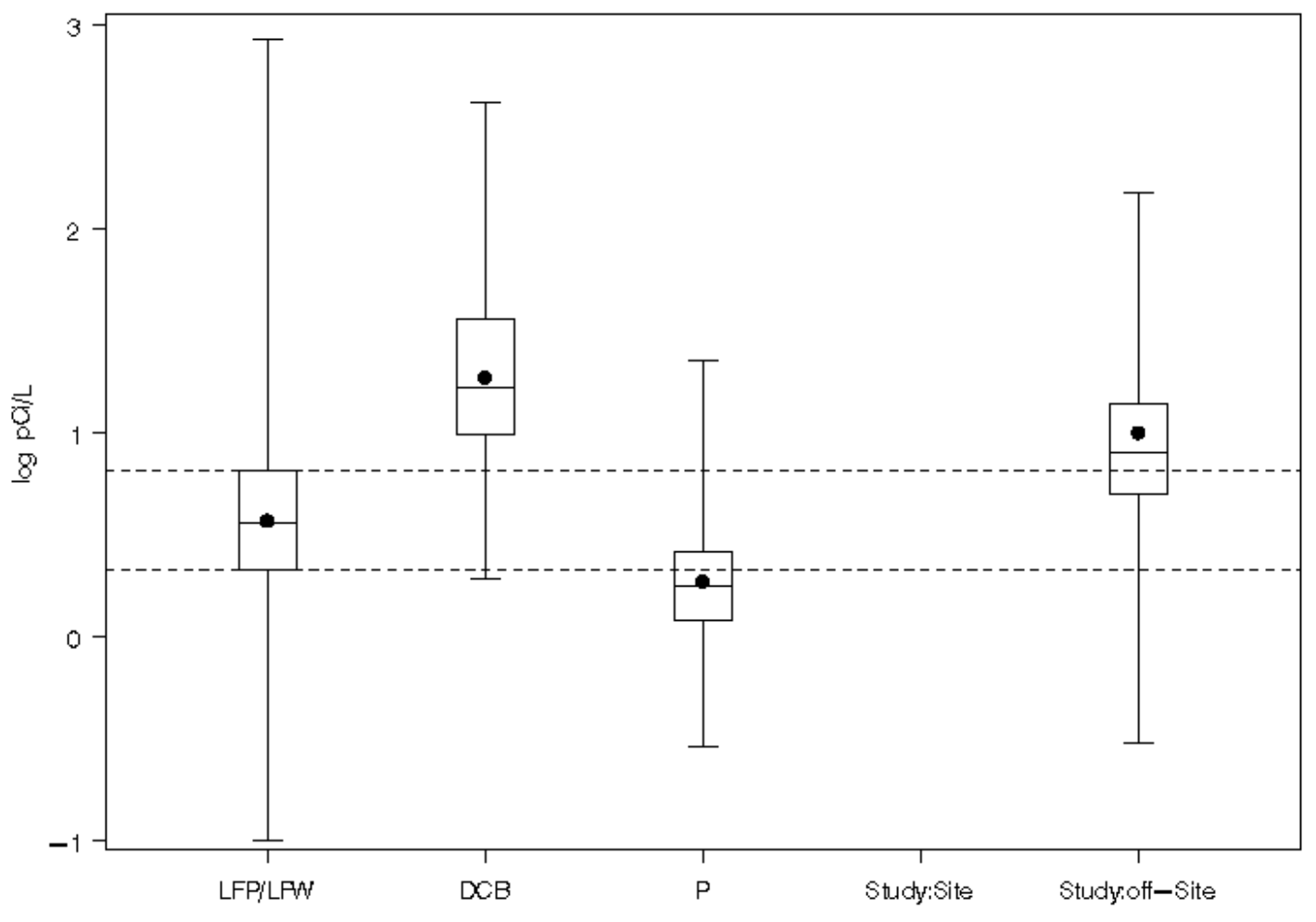

